\title{
The first fossil New World Dixidae with a critical discussion of generic definitions
}

\author{
Dale E. Greenwalt and John K. Moulton
}

\begin{abstract}
Four new fossil species of the dipteran family Dixidae, including the first fossil specimens of females in this family, are described from the Middle Eocene Kishenehn Formation oil shales of northwestern Montana. These new species, Dixella intacta sp. nov., $D$. eomarginata sp. nov., $D$. spinilobata sp. nov. and $D$. curvistyla sp. nov., are the first fossils of Dixidae to be described from the New World. The morphological bases of all generic assignments of extant and extinct dixids are critically reviewed, and new data on wing venation pattern variability in extant Dixidae are presented. It is concluded that it is impossible to distinguish between adults of the two major genera, Dixa and Dixella, based solely on wing venation. Given the lack of distinguishing features, the names of the two Cenozoic species that consist only of a single wing, Dixa priscula and $D$. cimbrica, are declared nomina dubia and the fossils are assigned to Dixidae incertae sedis.
\end{abstract}

Dale E. Greenwalt. Department of Paleobiology, National Museum of Natural History MRC 121, Smithsonian Institution, 10th \& Constitution Ave. NW, Washington, D.C. 20013-7012. GreenwaltD@si.edu John K. Moulton. The University of Tennessee, Entomology and Plant Pathology Department, 432 Biotechnology Bldg., 2505 E. J. Chapman Drive, Knoxville, TN 37996-4560. jmoulton@utk.edu

Keywords: Dixidae; Eocene insect fossil; Kishenehn Formation; venation; new species

Submission: 7 March 2016 Acceptance: 9 November 2016

\section{INTRODUCTION}

Meniscus midges (Diptera: Culicomorpha: Culicoidea: Dixidae Schiner, 1868) constitute a very small family of 197 species (184 extant) in nine genera (Pape et al., 2011) (Tables 1 and 2). Historically, Dixidae have been considered to be the sister taxon to the other Culicoidea (Ross, 1951), and this concept is supported by both biochemical (Rao and Rai, 1987, 1990) and phylogenetic studies in which Dixidae is the sister group to
Corethrellidae + (Culicidae + Chaoboridae) (Wood and Borkent, 1989; Oosterbroek and Courtney, 1995; Saether, 2000; Bertone et al., 2008; Woodley et al., 2009; Wiegmann et al., 2011; Borkent, 2012). A divergence time estimate of approximately $190 \mathrm{Ma}$, calculated from nuclear gene sequence data, appears conservative given the report of dixid fossils from the lowermost Jurassic (Lukashevich, 1996; Bertone et al., 2008). Fossil Chironomidae have been reported from the 202 Ma Lilstock Formation, Gloucestershire, UK

http://zoobank.org/3FEDC26A-677F-451E-AC95-341AC229C7C8

Greenwalt, Dale E. and Moulton, John K. 2016. The first fossil New World Dixidae with a critical discussion of generic definitions.

Palaeontologia Electronica 19.3.55A: 1-32

palaeo-electronica.org/content/2016/1698-new-world-fossil-dixidae

Copyright: December 2016 Palaeontological Association 
TABLE 1. Extant genera of the family Dixidae.

\begin{tabular}{lcl}
\hline \multicolumn{1}{c}{ Name } & Number of species & \multicolumn{1}{c}{ Geographical distribution } \\
\hline Asiodixa Papp et al., 2006 & 2 & Thailand \\
Dixa Meigen, 1818 & 106 & World-wide except Antarctica \\
Dixella Dyar \& Shannon, 1924 & 64 & World-wide except Antarctica \\
Meringodixa Nowell, 1951 & 1 & North America \\
Mesodixa Belkin, Heinemann \& Page, 1970 & 1 & Jamaica \\
Metadixa Peters and Savary, 1994 & 1 & Philippines \\
Neodixa Tonnoir, 1924 & 1 & New Zealand \\
Nothodixa Edwards, 1930 & 10 & Australia, Chile \& New Zealand \\
\hline
\end{tabular}

TABLE 2. Fossils of the family Dixidae.

\begin{tabular}{|c|c|c|c|c|}
\hline Name & Age & Lithology & Formation/Location & Reference \\
\hline Dixidae incertae sedis & Oligocene & Marl & Bouldnor Formation, U. K. & Cockerell, 1921 \\
\hline \multicolumn{5}{|c|}{ (Dixa priscula Cockerell, 1921. Nomen dubium) } \\
\hline Dixidae incertae sedis & $\begin{array}{l}\text { Paleocene/ } \\
\text { Eocene }\end{array}$ & Clayey diatomite & The Fur Formation, Denmark & Ansorge, 1992 \\
\hline \multicolumn{5}{|c|}{ (Dixa cimbrica Ansorge, 1992. Nomen dubium) } \\
\hline Dixa minuta & Late Eocene & Amber & The Baltic region (Europe) & Meunier, 1906 \\
\hline Dixa tertiaria & Oligocene & Marl & The d'Aix Formation, France & $\begin{array}{l}\text { Meunier, 1915; } \\
\text { Theobald, } 1937\end{array}$ \\
\hline \multicolumn{5}{|c|}{ (Dixa hyalipennis Theobald, 1937) } \\
\hline Dixella distans & Late Eocene & Amber & The Baltic region (Europe) & Hennig, 1966 \\
\hline Dixella filiforceps & Late Eocene & Amber & The Baltic region (Europe) & Hennig, 1966 \\
\hline Dixella intacta & Middle Eocene & Oil shale & Kishenehn Formation, U.S.A. & $\begin{array}{l}\text { Greenwalt \& Moulton, } \\
2016^{*}\end{array}$ \\
\hline Dixella eomarginata & Middle Eocene & Oil shale & Kishenehn Formation, U.S.A. & $\begin{array}{l}\text { Greenwalt \& Moulton, } \\
2016^{*}\end{array}$ \\
\hline Dixella spinilobata & Middle Eocene & Oil shale & Kishenehn Formation, U.S.A. & $\begin{array}{l}\text { Greenwalt \& Moulton, } \\
2016^{*}\end{array}$ \\
\hline Dixella curvistyla & Middle Eocene & Oil shale & Kishenehn Formation, U.S.A. & $\begin{array}{l}\text { Greenwalt \& Moulton, } \\
2016^{*}\end{array}$ \\
\hline Dixella succinea & Late Eocene & Amber & The Baltic region (Europe) & Meunier, 1906 \\
\hline Eucorethrina convexa & Late Jurassic & Shale & The Itat Formation, Siberia & Lukashevich, 1996 \\
\hline Eucorethrina flexa & Middle Jurassic & Shale & The Itat Formation, Siberia & $\begin{array}{l}\text { Kalugina \& Kovalev, } \\
1985\end{array}$ \\
\hline Eucorethrina westwoodi & Early Cretaceous & Shale & $\begin{array}{l}\text { Durlston \& Lulworth } \\
\text { Formations, U.K. }\end{array}$ & Lukasevich et al., 2001 \\
\hline ?Syndixa liasina & Middle Jurrasic & Shale & Dzhil Formation, Kyrgyzstan & Lukashevich, 1996 \\
\hline Syndixa mollis & Middle Jurassic & Shale & The Itat Formation, Siberia & Lukashevich, 1996 \\
\hline Syndixa sibirica & Early Jurassic & Shale & The Itat Formation, Siberia & Lukashevich, 1996 \\
\hline
\end{tabular}

*This study 
(Krzeminski and Jarzembowski, 1999), Chaoboridae from the 161-156 Ma Ichetuy Formation (Kalugina, 1985) and unidentified Culicomorpha from the $220 \mathrm{Ma}$ Cow Branch Formation in Virginia, USA (Blagoderov et al., 2007 but see Borkent, 2012 for reservations about assignment to the infraorder). A recent estimate places the divergence of the Culicomorpha at approximately 225 Ma (Wiegmann et al., 2011). No phylogenetic work, either morphological or molecular, has been done, at the intrafamilial level, on the family Dixidae.

The Mesozoic Dixidae (Table 2) consist of six species, all of which are based on isolated wings, in the two extinct genera Eucorethrina Kalugina, 1985 and Syndixa Lukashevich, 1996 (Kalugina, 1985; Lukashevich, 1996). None of the six species exhibits the strongly arched $R_{2+3}$ vein that is the only recognized synapomorphy of the recent adult members of the family (Peters and Cook, 1966). Note that the holotype of E. westwoodi Lukashevich, Coram and Jarzembowski, 2001 has a slightly arched $R_{2+3}$ while $R_{2+3}$ in its figured paratype is straight (Lukashevich et al., 2001). The wing venation of Eucorethrina is otherwise very similar to that of extant genera; criteria in the original diagnosis by Kalugina (1985) such as Sc proximal to r-m and $\mathrm{A}_{1}$ proximal to the bifurcation of $\mathrm{Cu}$ are plesiomorphies commonly encountered in extant Dixidae and other Diptera. $R_{1}$ and $R_{2}$ converging at the wing margin, another criterion of the original diagnosis, is uncommon in extant Dixidae although it, and all other criteria in the original diagnosis, are found in Nothodixa Edwards, 1930 (Belkin, 1968). The convergence of $R_{1}$ and $R_{2}$ is not found in some specimens of Eucorethrina figured by Lukashevich (1996). Lukashevich et al. (2001) amended the diagnosis of Eucorethrina to Sc ending distal to Rs origin and the apex of $R_{1}$ equidistant from the apices of $\mathrm{C}$ and $\mathrm{R}_{2}$. Again however, Eucorethrina flexa Kalugina, 1985, as figured by Kalugina (1985) and Eucorethrina westwoodi as figured by Lukashevich et al. (2001), have Sc only slightly distad of the Rs origin, a configuration also found in the extant species Dixella shannoni Lane, 1942 and D. hernandezi Chaverri and Borkent, 2007. The criterion apex of $R_{1}$ equidistant from the apices of $C$ and $R_{2}$, which is figured but not commented on by Kalugina (1985), appears to be unique to Eucorethrina; in all extant Dixidae, R1 is closer to $C$. The venation of the extinct genus Syndixa is indistinguishable from that of Eucorethrina but for the defining fusion of $R_{2}$ with $R_{1}$. Three different species of Syndixa have been established, with two of the three based on a single specimen. Given the fusion of $R_{1}$ and $R_{2}$, "like in Chironomoidea," Lukashevich (1996) has suggested that "Syndixa could be related to ancestors of the Chironomoidea." If this is indeed the case, inclusion of Syndixa in Dixidae renders this family paraphyletic.

Of the seven previously described Cenozoic fossil species, four are inclusions in Baltic amber and three species are compression fossils found in Denmark, France, and England. These specimens are discussed in greater detail below. All extant members of the family are restricted to wet environments such as streams, lakes, swamps, etc. (Belkin, 1968). The larvae require free standing water to feed and swim. None of the Dixidae is known to be of economic or medical/veterinary importance; as a result very little is known about the biology of most species despite their earlier inclusion, as a subfamily, in the Culicidae (Peters, 1981). The classification of the extant Dixidae has been referred to as "chaotic" and "confused," and classification of the Dixidae has long been known to be in need of major revision (Belkin, 1968; Belkin et al., 1970, Chaverri and Borkent, 2007). The largest genera, Dixa Meigen, 1818 and Dixella Dyar and Shannon, 1924, which contain more than $90 \%$ of extant Dixidae (Table 1), have been assumed to be polyphyletic (Belkin, 1968). In the present study, the generic assignments of the Eocene fossil dixids are reviewed, and data are presented to further document wing venation variability and the inability to discriminate between the major genera based soley on wing venation.

The oil shale of the Coal Creek Member of the Kishenehn Formation, dated to the Middle Eocene (approximately $46 \mathrm{Ma}$ ), was shown to contain fossil insects a quarter of a century ago (Constenius et al., 1989). However, extensive collection from exposures of the Coal Creek member has only recently taken place. An apparent taphonomic bias towards the preservation of particularly small insects has permitted recent descriptions of the first compression fossils of Mymaridae (Hymenoptera: Chalcidoidea), Culiseta Felt, 1904 (Diptera: Culicidae) and specimens of the smallest of all beetles (Coleoptera: Ptiliidae) from the Kishenehn Formation (Huber and Greenwalt, 2011; Harbach and Greenwalt, 2012; Shockley and Greenwalt, 2013). The environment that existed when the Kishenehn sediments were deposited was seasonal subtropical/tropical. Sediments formed in a shallow near-shore environment that exhibited little or no water flow (Greenwalt et al., 2015). 


\section{MATERIALS AND METHODS}

Specimens described herein as new species were collected from the Deep Ford, Dakin, and Disbrow Creek sites on the Middle Fork of the Flathead River in northwestern Montana between 2009 and 2012 in accordance with USFS Authorization HUN281. Exposures there are from the middle sequence of the Coal Creek member of the Kishenehn Formation, which has been estimated to be $46.2 \pm 0.4 \mathrm{Ma}$ by ${ }^{40} \mathrm{Ar} /{ }^{39} \mathrm{Ar}$ analysis and $43.5 \pm 4.9$ Ma by fission-track analysis (Constenius, 1996). Specimens were photographed with an Olympus SZX12 microscope equipped with a Q-Color5 Olympus camera. Image-Pro Plus 7.0 software (Media Cybernetics, Inc., Bethesda, MD) was used to capture and record the images. Fossils were immersed in $95 \%$ ethanol for examination and photography. Measurements were made with the Image-Pro Plus 7.0 software. Venational terminology is from McAlpine (1981). Ratios $R_{2} / M_{2}, M_{2} / M_{1}$, $M_{2} / M_{1+2}$, and $R_{2+3} / R_{3}$, are those defined by Peters and Cook (1966). Dixa priscula Cockerell, 1921 (specimen \# H.708) was examined at the Natural History Museum, London. Abbreviations used are $\mathrm{F}=$ flagellomere; $\mathrm{L}=$ Latin; $\mathrm{L} / \mathrm{W}=$ length to width ratio; $\mathrm{Ma}=$ million years ago; $\mathrm{MSC}=$ Museum Support Center of the Smithsonian Institution's National Museum of Natural History, Suitland, MD; $\mathrm{NHM}=$ Natural History Museum, London; NMNH = National Museum of Natural History, Washington DC; WRBU = Walter Reed Biosystematics Unit.

Representatives of seven extant genera and all extinct species (116 total species, Appendix 1) were scored for 13 characters of the wings, mostly those of venation. Characters (Appendix 2) were coded as binary or multistate; if a particular character state could not be determined, a dash (-) was entered in the matrix to indicate missing data. Elimination of characters found only in extinct genera and extant genera other than Dixa and Dixella resulted in a subset of seven of the 13 characters (characters 1-6 and 9 in Appendix 2) that were then used in the comparative analysis of wing venation variability. The comparative analysis was confined to the 91 extant species of the two genera Dixa and Dixella listed in Appendix 1. Forty-nine species of Dixa and Dixella were accessed from collection at the Walter Reed Biosystematics Unit (WRBU) of the Smithsonian Institution's Museum Support Center (MSC) in Suitland, MD. When more than a single specimen was examined (for example in the study of intraspecific variability), they were selected at random. Data for an additional 65 species, not including Dixa priscula and the four new species described herein, were obtained from holotype descriptions available in the literature. In an attempt to document intraspecific venation pattern variability, seven species were selected at random from specimens housed at the WBRU from among those that had a minimum of 10 specimens/species. Between three and 16 randomly selected specimens were examined per species. Generic assignments are based on the original literature and specimen labels. The purpose of these analyses was simply to determine and document the degree of variability of these seven characters either between the two major genera of the family, Dixa and Dixella, or within a single species. Given the high degree of variability observed in this study, a phylogenetic analysis of the data was deemed futile and unproductive and was not attempted.

\section{RESULTS}

\section{Systematic Palaeontology}

Order DIPTERA Linnaeus, 1758

Family DIXIDAE Schiner, 1868

Genus DIXELLA Dyar and Shannon, 1924

Type species. Dixella lirio Dyar and Shannon, 1924

Dixella intacta Greenwalt and Moulton, new species

Figures 1, 2, 3.1, 4.1, 5

zoobank.org/B50B1127-CA1E-4395-9A74-60B1AD5701CE

Etymology. The specific epithet is Latin for "untouched", an indication of the intact nature of this fossil.

Holotype. Dixella intacta Greenwalt and Moulton, female; NMNH, USNM 546204.

Type Horizon. Middle Eocene Coal Creek member, Kishenehn Formation.

Type Locality. Deep Ford site, Middle Fork of the Flathead River (Pinnacle, Montana).

Differential Diagnosis. Distinguished from all other fossil Dixidae based on the presence of one or more of the following character states: distinct stylized spade-shaped cercus (similar to Dixa brevis Garrett, 1924), first flagellomere very slightly fusiform, antenna length much more than combined lengths of head and thorax, wing length/body length ratio equal to one, and apex of $R_{1}$ closer to $C$ than to $R_{2}$.

Description. Adult female (Figure 1), body length $4.5 \mathrm{~mm}$.

Head. Black. Eyes dichoptic, large, oval with dorsal-ventral height $(0.45 \mathrm{~mm})$ greater than width 


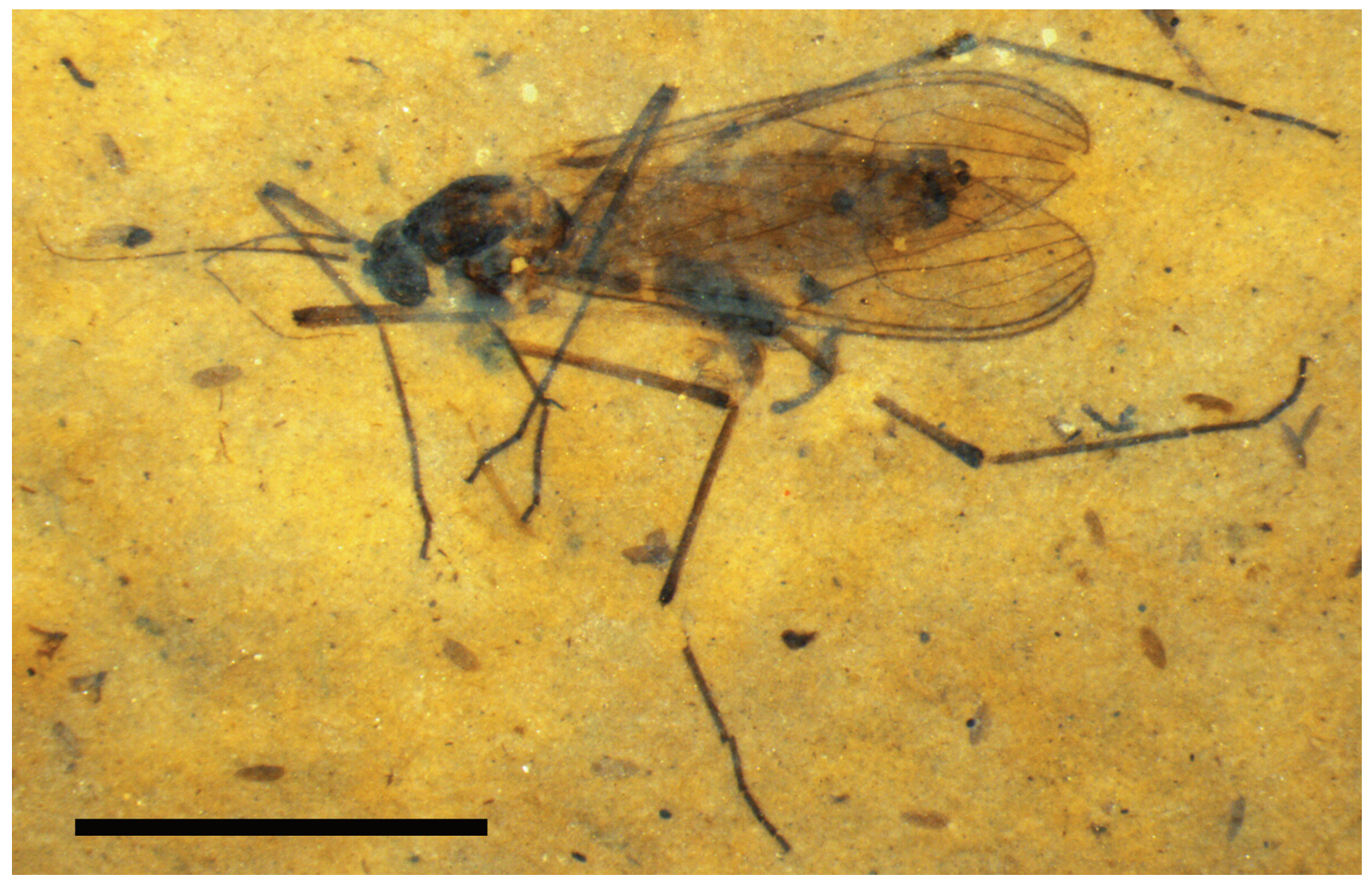

FIGURE 1. Habitus of Dixa intacta, holotype. Scale bar equals $3 \mathrm{~mm}$.

$(0.40 \mathrm{~mm})$. Eyes separated by $0.12 \mathrm{~mm}$. Maxillary palpus not visible. Antenna brown, $2.4 \mathrm{~mm}$ in length (Figure 2.1). Scape barely visible, small, approximately $40 \mu \mathrm{m}$ in width. Pedicel subspherical, $104 \mu \mathrm{m}$ wide, $118 \mu \mathrm{m}$ long. Antenna with 14 flagellomeres, each setose. F1 very slightly fusiform, $40 \mu \mathrm{m}$ wide; F2-F4 widths gradually decrease to $30 \mu \mathrm{m}$. F5 $(22 \mu \mathrm{m})$ more slender than F4. F5, subsequent flagellomere widths gradually decrease to $7 \mu \mathrm{m}$ at F14. Flagellomere lengths/ widths (in $\mathrm{mm}$ ) as follows: F1 (0.30/0.04), F2 (0.12/ $0.04)$, F3 (0.16/0.03), F4 (0.17/0.03), F5 $(0.23 /$ $0.02), \quad$ F6 $(0.20 / 0.02), \quad$ F7 $\quad(0.19 / 0.02), \quad F 8$ (0.190.01), F9 (0.18/0.01), F10 (0.15/0.01), F11 $(0.13 / 0.01), F 12(0.12 / 0.01), F 13(0.12 / 0.01), F 14$ $(0.13 / 0.01)$.

Thorax. Length $1.3 \mathrm{~mm}$. Dark brown medial, lateral vittae covering most of scutum except for posteromedial portion and four medial light brown spots connecting medial, lateral vittae (Figure 2.2). Scutellum yellow. Acrostichal setae at lateral margin of medial vitta. Setae present along posterior margin of scutellum, lateral surface of mediotergite. Wings. Length $4.28 \mathrm{~mm}$, width $1.37 \mathrm{~mm}$ (Figure 3.1). L/W ratio $=3.12$. Vein $R_{2+3}$ arched. Sc apex even with Rs origin. Crossvein r-m single vein- width distal to Rs bifurcation, slightly sigmoidal. Crossvein m-cu even with posterior point of r-m. A1 apex slightly basal to $\mathrm{Cu}$ bifurcation, distal to $\mathrm{Sc}$ apex and $R s$ origin. $R_{2+3}$ bifurcation basal to $M$ bifurcation. Length ratios $R_{2} / M_{2}, M_{2} / M_{1}, M_{2} / M_{1+2}$, $\mathrm{R}_{2+3} / \mathrm{R}_{3}=2.6,0.61,0.54,0.49$, respectively. Vein CuP present. Wing surface covered with microtrichae; veins, margin of wing with spiniform setae $55 \pm 15 \mu \mathrm{m}$ in length. Haltere dark brown, length $0.59 \mathrm{~mm}$ with setae on anterior margin of proximal end, knob; knob spherical, diameter $155 \mu \mathrm{m}$; base black.

Legs. All legs setose; hind tibia expanded distally. Foreleg femur, tibia, 5 tarsomeres lengths 1.38, $1.32,0.9,0.36,0.23,0.12,0.14 \mathrm{~mm}$, respectively. Midleg femur, tibia, 5 tarsomeres lengths 1.74 , $1.58,0.76,0.42,0.27,0.14,0.15 \mathrm{~mm}$, respectively. Hind leg femur, tibia, 5 tarsal segments lengths 1.8, $1.83,1.52,0.53,0.34,0.18,0.13 \mathrm{~mm}$, respectively. Claws without teeth (Figure 4.1).

Abdomen and genitalia. Abdomen brown, setose, length $2.84 \mathrm{~mm}$ (not including cercus); sternite 8, tergite 9 dark brown/black, more heavily setose than anterior portion of abdomen. With single sclerotized spermatheca, spherical, $0.17 \mathrm{~mm}$ in diame- 


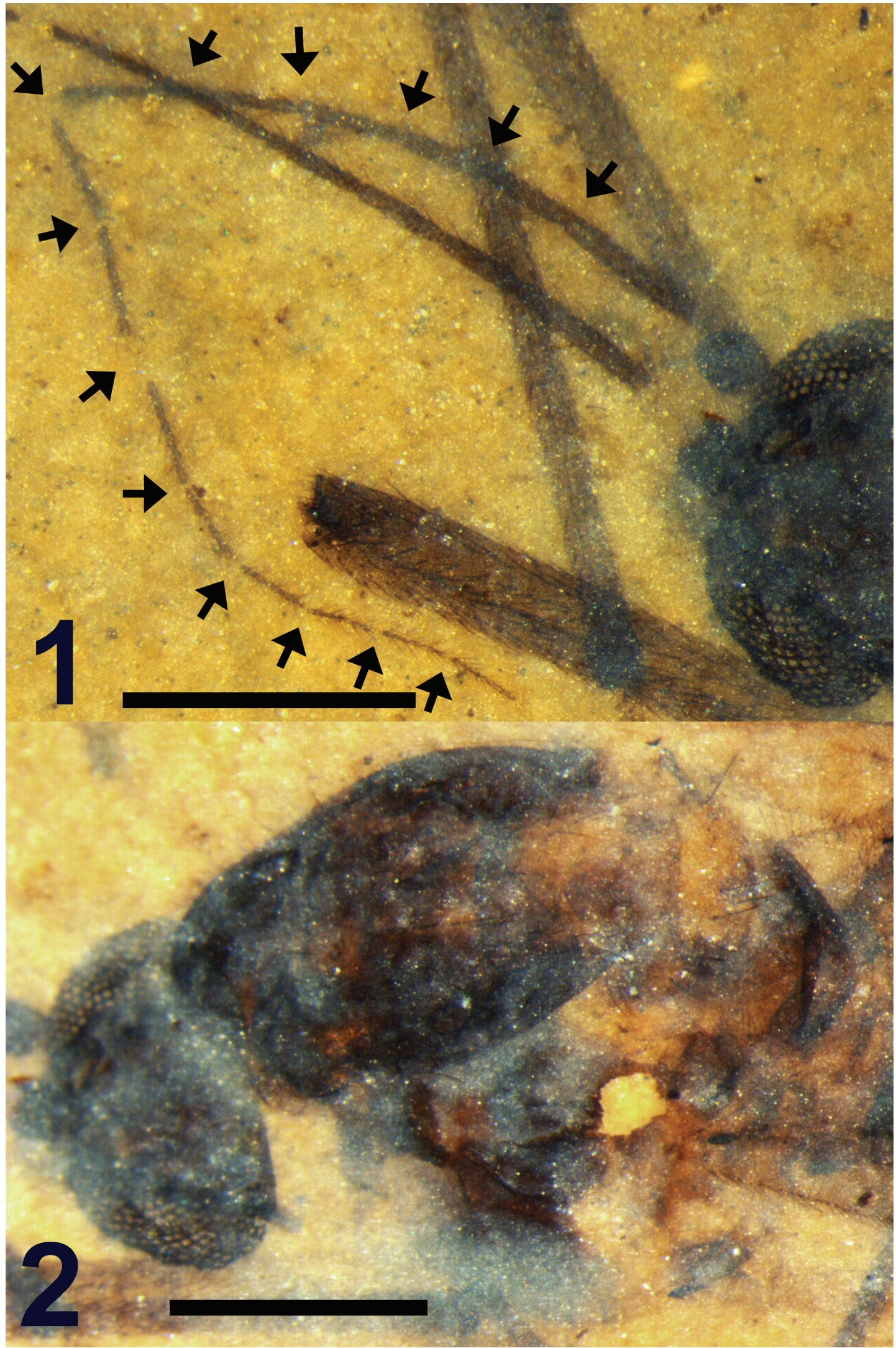

FIGURE 2. Morphological features of Dixa intacta. 1, Antennae with individual flagellomeres delineated; 2, Dorsal aspect of the thorax. Scale bars equal $0.5 \mathrm{~mm}$ for both figures. 


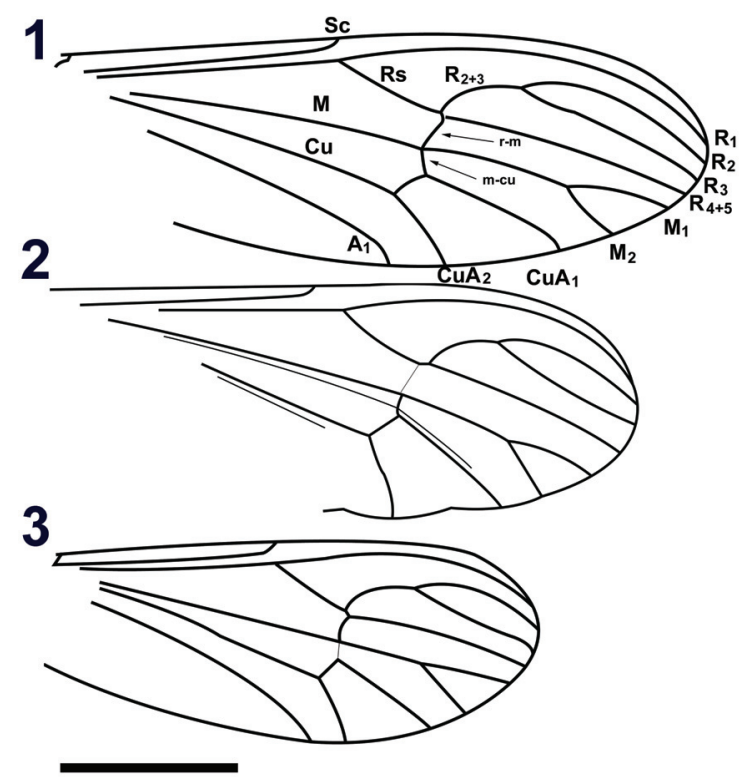

FIGURE 3. Line drawings of wings. 1, Dixella intacta; 2, $D$. eomarginata; $3, D$. curvistyla. Wing venation is from McAlpine (1981). Scale bar equals $1 \mathrm{~mm}$.

ter. Cercus black, setose, shaped like stylized spade, length $0.12 \mathrm{~mm}$ (Figure 5).

Male unknown.

Dixella eomarginata Greenwalt and Moulton, new species

Figures 3.2, 6, 7

zoobank.org/0EC67728-2799-4615-B318-3723C944DE99

Etymology. The specific epithet is a combination of the Greek term eos, meaning dawn, and the specific epithet marginata, indicating similarity of the shape of the posterior margin of the wing with that of the extant Dixella marginata Loew, 1863.
Holotype. Dixella eomarginata Greenwalt and Moulton, female; NMNH, USNM 553521.

Type Horizon. Middle Eocene Coal Creek member, Kishenehn Formation.

Type Locality. Dakin site, Middle Fork of the Flathead River (Pinnacle, Montana).

Differential Diagnosis. Distinguished from all other fossil Dixidae based on the presence of the following character states: wing emarginate between $\mathrm{CuA} 1$ and $\mathrm{CuA} 2$, wing length to body length ratio equal to $0.91, R_{1}$ closer to $C$ than $R_{2}$.

Description. Adult female (Figure 6), body length $3.8 \mathrm{~mm}$.

Head. Black. Eyes dichoptic, spherical, diameter $0.26 \mathrm{~mm}, 0.12 \mathrm{~mm}$. Maxillary palps not visible. Antennae not preserved intact, contiguous flagellomeres present, brown, filiform. Pedicel light brown, longer than wide. One maxillary palp present, poorly preserved, length $0.5 \mathrm{~mm}$; length terminal segment $0.179 \mathrm{~mm}$.

Thorax. Lateral view. Length $1.03 \mathrm{~mm}$, black; lateral vittae absent; scutellum brown. Thoracic setae not visible.

Wings. Length $3.46 \mathrm{~mm}$ (measured from base of humeral crossvein), width $1.18 \mathrm{~mm}$ (Figures 3.2 , 7.1). L/W ratio $=2.93$. Vein $R_{2+3}$ arched. Vein Sc apex basal to origin of Rs (1.4 times distance between $\mathrm{C}, \mathrm{R} 1$ ). Crossvein r-m basal to Rs bifurcation. Crossvein $\mathrm{m}$-cu very lightly sclerotized, apex just distal to $r-m$ terminus. A1 apex poorly preserved, basal to $\mathrm{Cu}$ bifurcation, distal to Sc apex. $R_{2+3}$ bifurcation significantly basal to $M$ bifurcation. Ratios $R_{2} / M_{2}, M_{2} / M_{1}, M_{2} / M_{1+2}, R_{2+3} / R_{3}=2.37,0.71$, $0.55,0.44$, respectively. Wing veins, margin with thin setae, length $\leq 20 \mu \mathrm{m}$. Wing posterior margin emarginate between CuA1, CuA2. Prominent false vein (?) between $M, C u$ continues between $M_{1+2}$,

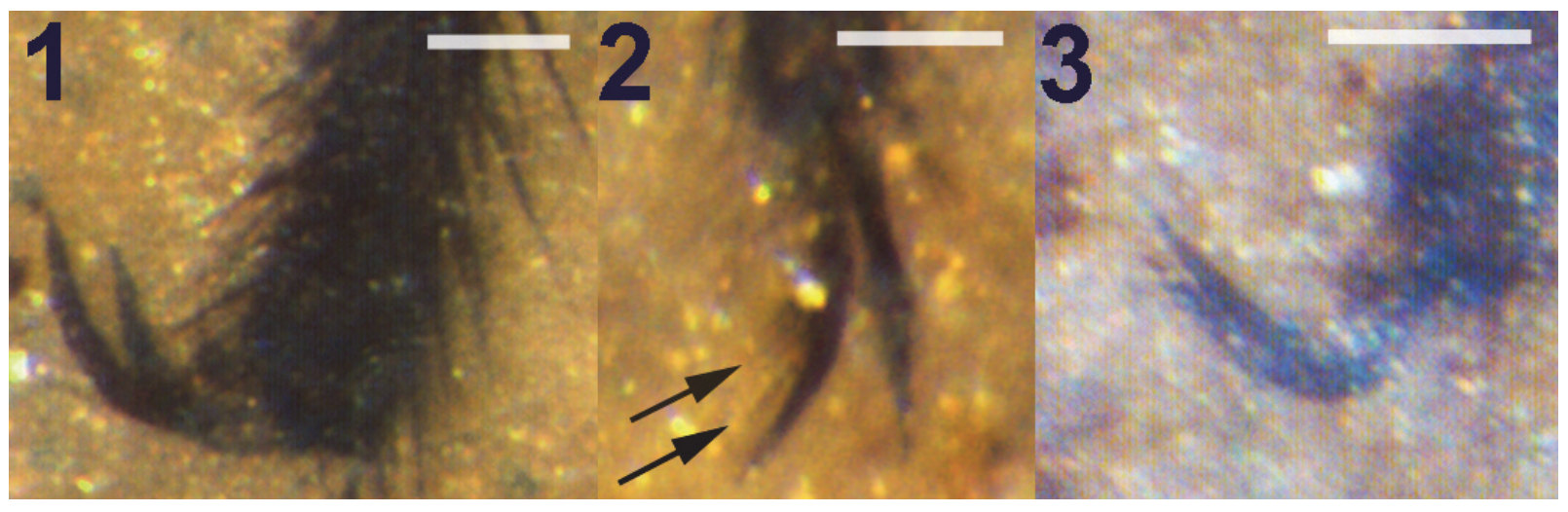

FIGURE 4. Tarsal claw teeth of the Kishenehn Dixella. 1, Dixella intacta left metatarsal claw; 2, D. curvistyla left metatarsal claw; 3, D. spinilobata right metatarsal claw. Arrows point to teeth. Scale bars equals $50 \mu \mathrm{m}$. 


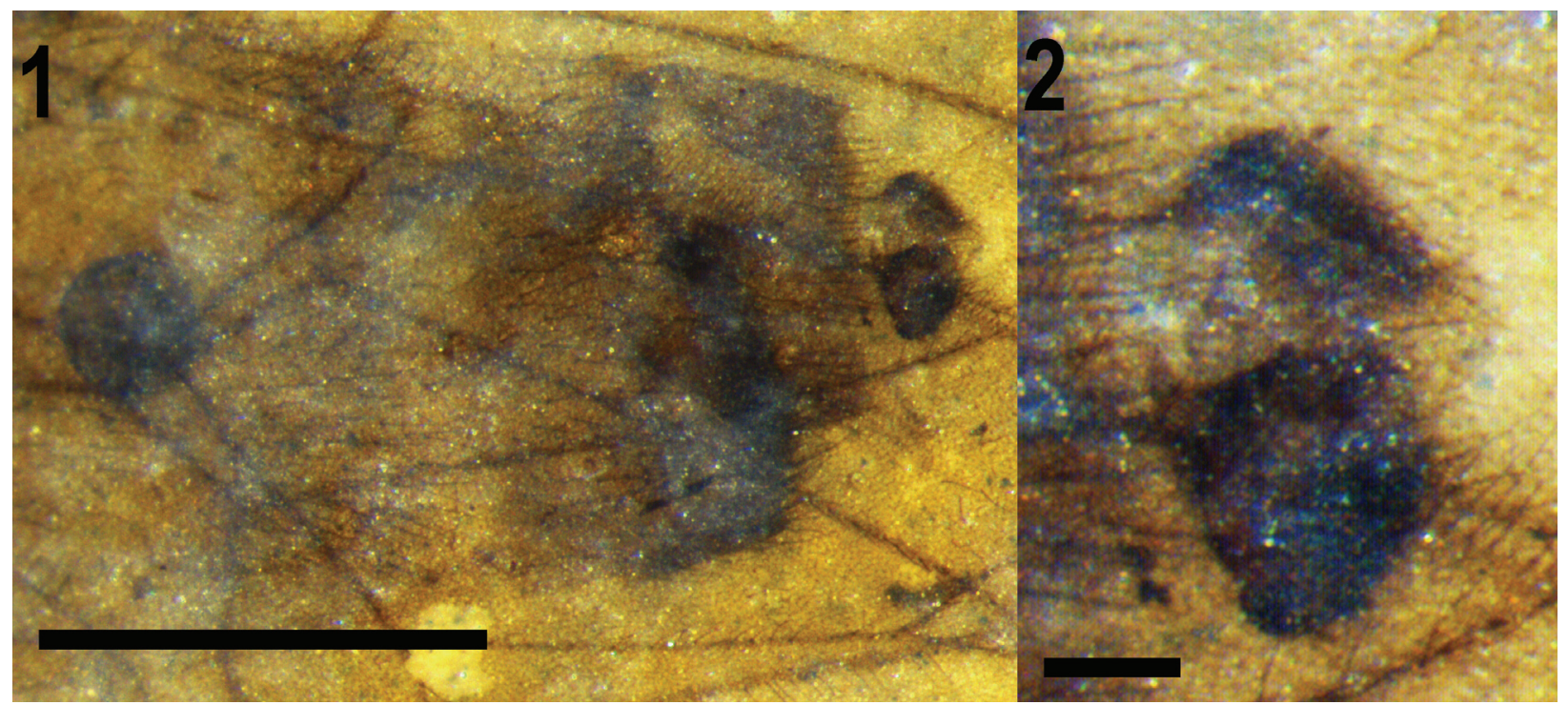

FIGURE 5. The terminalia of Dixa intacta. 1, Posterior portion of abdomen including the spermatheca; 2, Cerci. Scale bars equal $0.5 \mathrm{~mm}(1)$ and $0.05 \mathrm{~mm} \mathrm{(2).}$

$\mathrm{CuA}_{1}$ (not present in the right wing). Haltere brown, length $0.53 \mathrm{~mm}$ long, knob oval, width $144 \mu \mathrm{m}$, length wide $207 \mu \mathrm{m}$.

Legs. All legs setose; metatibia expanded distally. Foreleg femur, tibia, tarsus lengths 1.28, 1.29, 1.65 $\mathrm{mm}$, respectively. Midleg femur, tibia, tarsus lengths $1.71,1.40,1.78 \mathrm{~mm}$, respectively. Hind leg femur, tibia, tarsus lengths $1.65,1.56,2.22 \mathrm{~mm}$, respectively. Metapretarsal claws not preserved sufficiently to determine presence, absence of teeth.

Abdomen and genitalia. Abdomen light brown, length $2.66 \mathrm{~mm}$ (not including cerci). Segment 7 with single sclerotized spermatheca, oval, $154 \mu \mathrm{m}$ x $115 \mu \mathrm{m}$. Tergite 9, posterior edge sternite 8 dark brown/black, more heavily setose than anterior portions of abdomen. Cerci dorsally situated, brown, setose, length $0.12 \mathrm{~mm}$ (Figure 7.2). Posterior margin sternite 8 lined by numerous setae approximately $35 \mu \mathrm{m}$ long, Cerci, tergite 9 with several setae $70 \mu \mathrm{m}$ or longer. Sternite 9 bulbous, protruding just below cerci.

Male unknown.

Dixella curvistyla Greenwalt and Moulton, new species

Figures 3.3. 4.2, 8, 9

\section{zoobank.org/716DBCD1-3920-42D3-949D-BEC02984A27F}

Etymology. The specific epithet is derived from a combination of the terms curvi $(L)$ meaning curved and stylus (L) meaning stalk or pike, and denotes the sharply curved gonostylus of this species.
Holotype. Dixella curvistyla Greenwalt and Moulton, male; NMNH, USNM 546860.

Type Horizon. Middle Eocene Coal Creek member, Kishenehn Formation.

Type Locality. Disbrow Creek site, Middle Fork of the Flathead River (Pinnacle, Montana).

Differential Diagnosis. Distinguished from the three previously described Eocene fossil Dixella based on wing width $(1.32 \mathrm{~mm}$ vs. 0.56 in $D$. distans Hennig, 1966), length of flagellomere F1 $(0.234 \mathrm{~mm}$ vs. $0.415 \mathrm{~mm}$ in $D$. succinea Meunier, 1906) and form of the gonostylus (very long and narrow in $D$. filiforceps Hennig, 1966).

Description. Adult male (Figure 8), body length $3.36 \mathrm{~mm}$.

Head. Black. Eyes dichoptic, large, oblong, width $0.186 \mathrm{~mm}$, length $0.284 \mathrm{~mm}$. Three prominent setae at lateral margin of eye. Maxillary palp length $0.34 \mathrm{~mm}$, two basal segments wider than long (31 $x 41 \mu \mathrm{m}$ ); segments three and four 42 and $54 \mu \mathrm{m}$ long, respectively, both $35 \mu \mathrm{m}$ wide; terminal segment length $0.169 \mathrm{~mm}$, width $21 \mu \mathrm{m}$, terminus with several short setae (Figure 9.1). Most distal flagellomeres missing (Figure 9.1). Scape black, large, subspherical, $72 \mu \mathrm{m}$ in diameter. Pedicel black, globular, diameter $0.1 \mathrm{~mm}$. Flagellomeres setose, light brown. F1 cylindrical, diameter $32 \mu \mathrm{m}$, length $0.23 \mathrm{~mm}$. F2-F4 gradually decreasing in diameter. Thorax. Lateral view. Black, length $1.08 \mathrm{~mm}$, no setae apparent.

Wings. Length $2.89 \mathrm{~mm}$ (measured from base of the humeral crossvein), $1.17 \mathrm{~mm}$ wide. $\mathrm{L} / \mathrm{W}$ ratio $=$ 2.47. Vein $R_{2+3}$ arched (Figure 3.3). Vein Sc apex 


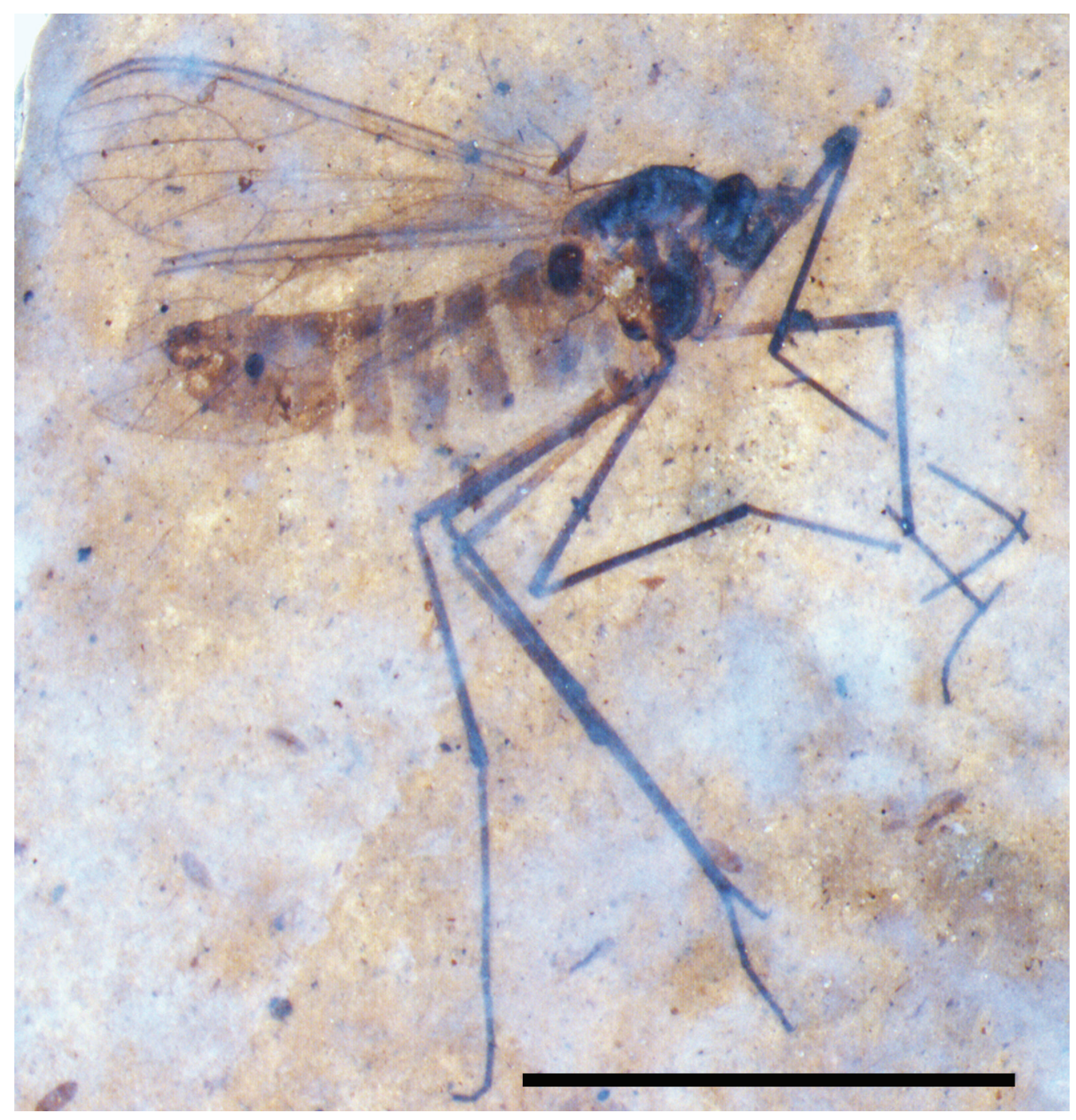

FIGURE 6. Habitus of Dixella eomarginata, holotype. Scale bar equals $3 \mathrm{~mm}$.

even with Rs origin. Crossvein r-m distal to Rs bifurcation. Crossvein m-cu even with $r-m$ apex, less heavily pigmented than $\mathrm{r}-\mathrm{m}$. A1 apex slightly basal to Cu bifurcation, distal to Sc apex, Rs origin. $R_{2+3}$ bifurcation even with $M$ bifurcation. Ratios $R_{2} /$ $M_{2}, M_{2} / M_{1}, M_{2} / M_{1+2}, R_{2+3} / R_{3}=2.03,0.70,0.75$, 0.52 , respectively. Wing surface infuscate; veins, except $\mathrm{M}, \mathrm{Cu}$, margin of wing covered with setae. Haltere dark brown, length $0.48 \mathrm{~mm}$; knob oblong, diameter $119 \mu \mathrm{m}$.

Legs. All legs setose, brown. At least two legs, including left hind leg, with tarsal claws with four observable teeth (Figure 4.2). All legs mostly disarticulated; mid and hind tarsi identification based on swollen apical portion of metatibia, combined fragment lengths. The foreleg femur, tibia lengths 1.08 and $1.0 \mathrm{~mm}$, respectively. Midleg femur, tibia, tarsus lengths $1.50,1.13 \mathrm{~mm}, 1.70 \mathrm{~mm}$, respectively. Hind leg femur, tibia, and tarsus lengths $1.30,1.26$, $1.9 \mathrm{~mm}$, respectively.

Abdomen and genitalia. Abdomen brown, setose, length $2.35 \mathrm{~mm}$ (including genitalia). Anterior half of abdomen with light bands of varying widths wherein setae are absent or reduced. Sternite 9 posterior margin with numerous setae. Gonocoxite length $220 \mu \mathrm{m}$, apical lobe length $79 \mu \mathrm{m}$, width 24 $\mu \mathrm{m}$ (Figure 9.2), distal margin with several prominent setae, each about $10 \mu \mathrm{m}$ in length. Gonostylus length $158 \mu \mathrm{m}$, very broad, base $79 \mu \mathrm{m}$, midpoint $54 \mu \mathrm{m}$, bent approximately 75 degrees at midpoint, tapering to very fine point.

Female unknown. 


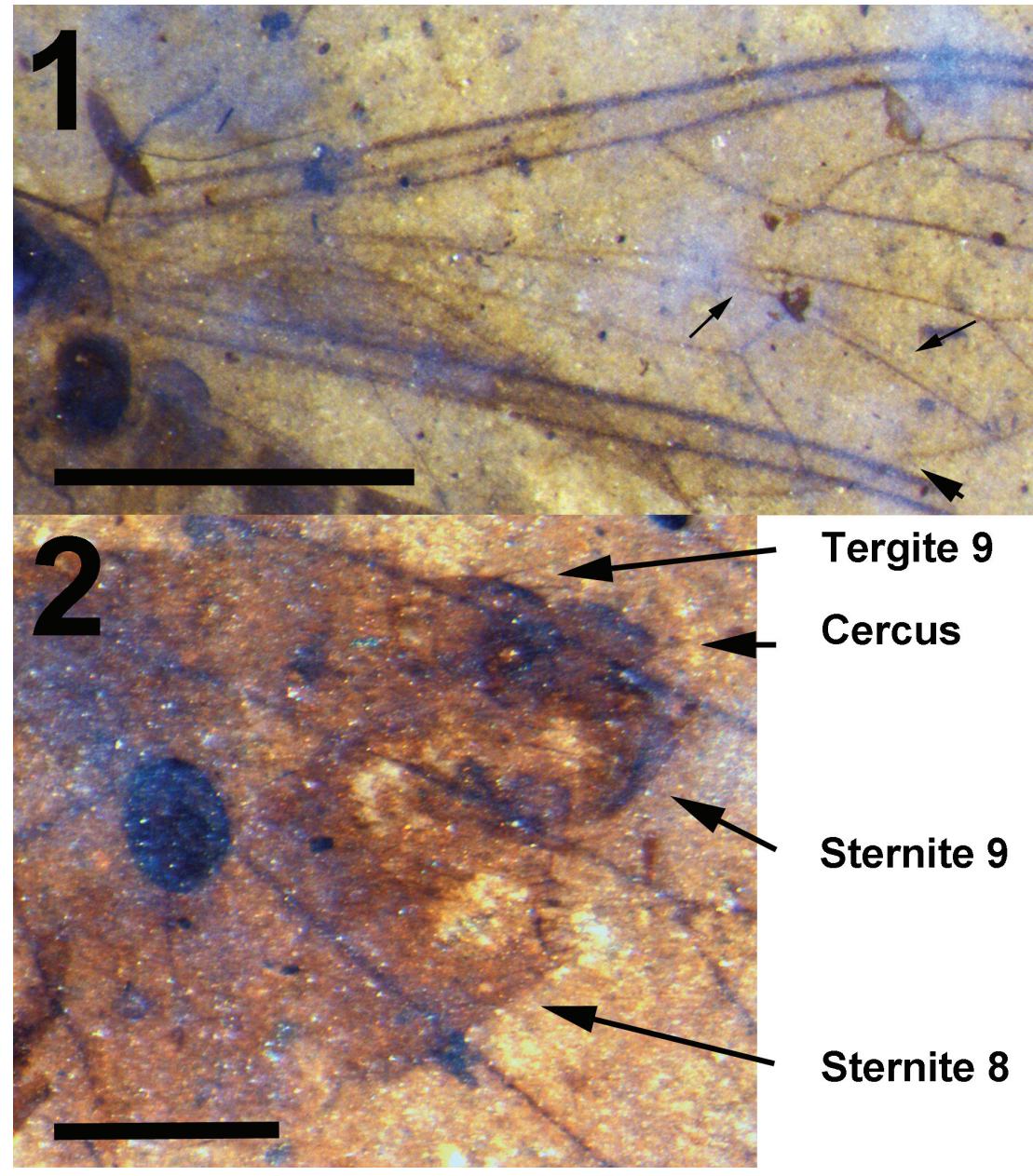

FIGURE 7. Morphological features of Dixa eomarginata. 1, Wing with an emarginate posterior margin (arrowhead); arrows denote an apparent false vein posterior to vein M. 2, Terminalia. Scale bars equal $1.0 \mathrm{~mm}$ (1) and $0.25 \mathrm{~mm}(2)$

Dixella spinilobata Greenwalt and Moulton, new
species

Figures 4.3, 10, 11

zoobank.org/E669A17A-4957-483C-ACC4-5E8BDF6CDF7A

Etymology. The specific epithet is derived from a combination of the terms spinosa (L) meaning spiny and lobata $(L)$ meaning lobed and refers to the spiniform shape of both the apical lobe and the tip of the basal lobe of the gonocoxite.

Holotype. Dixella spinilobata Greenwalt and Moulton, male; NMNH, USNM 553522.

Type Horizon. Middle Eocene Coal Creek member, Kishenehn Formation.

Type Locality. Dakin site, Middle Fork of the Flathead River (Pinnacle, Montana).

Differential Diagnosis. Distinguished from all other known fossil Dixidae based on one or more of the following characters: first flagellomere filliform, wing length to body length ratio equal to 0.95 ,
$R_{1}$ much closer to $C$ than $R_{2}$, antennal length ( 0.61 of its total body length), size of the gonocoxite and shape of the gonostylus.

Description. Adult male (Figure 10), body length $3.5 \mathrm{~mm}$

Head. Black; eyes dichoptic, large, spherical, diameter $0.222 \mathrm{~mm}$. Maxillary palps long, length $0.34 \mathrm{~mm}$, basal most segments not visible; segments four and five $88 \times 40$ and $230 \times 27 \mu \mathrm{m}$ (length $x$ width), respectively. Antenna brown, relatively long (2.12 mm; Figure 10), thin. Scape and pedicel poorly resolved, pedicel spherical, $73 \mu \mathrm{m}$ in diameter. Both F1 apparently filiform although partially covered by foreleg; dimensions unknown. Widths F2-F14 gradually decreasing. All flagellomeres setose.

Thorax. Length $0.95 \mathrm{~mm}$, black with dark brown medial, lateral vittae covering scutellum; scutellum light brown. Setae absent. 


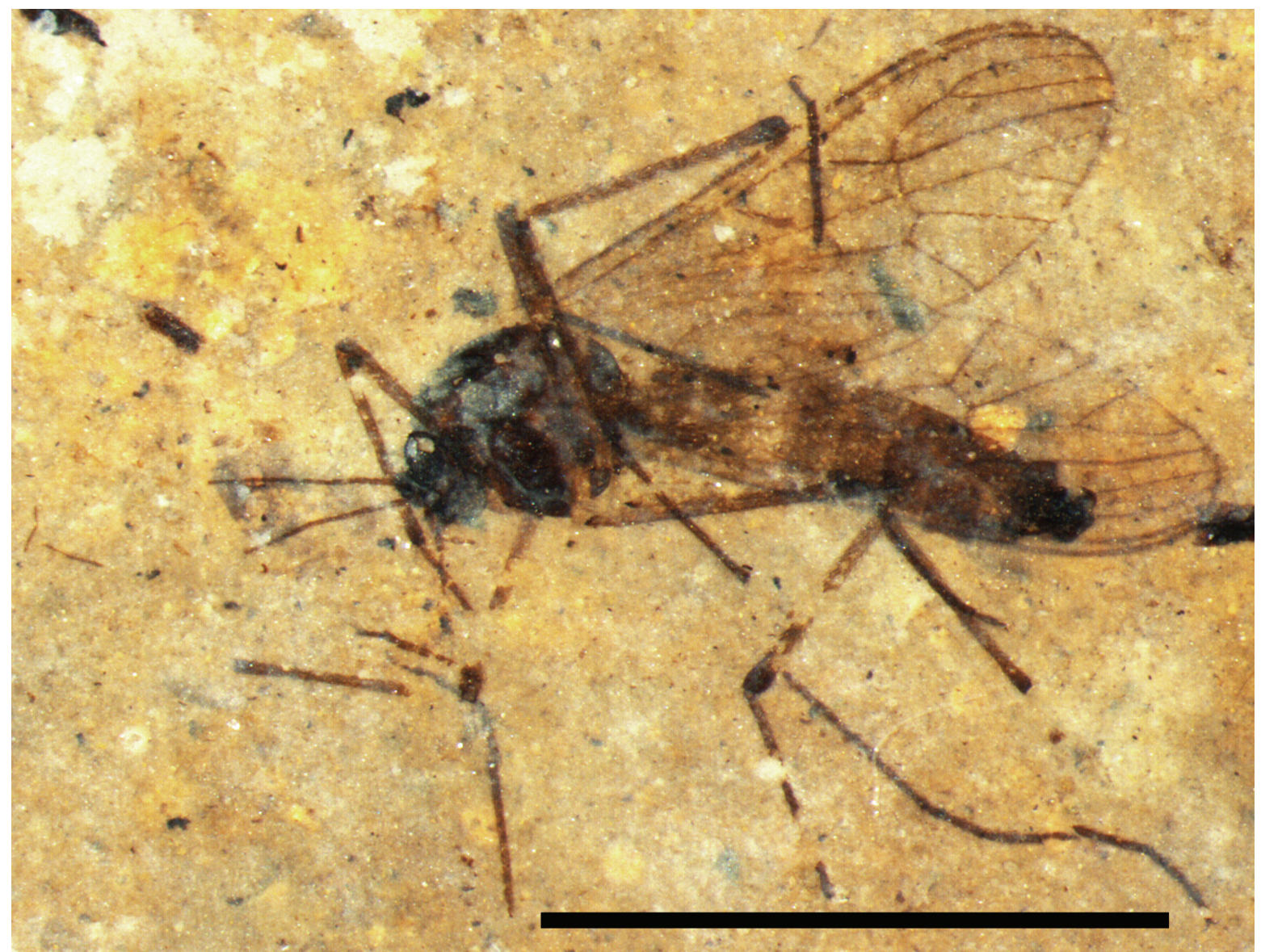

FIGURE 8. Habitus of Dixella curvistyla, holotype. Scale bar equals $3 \mathrm{~mm}$.

Wings. Length $3.32 \mathrm{~mm}$, width $1.08 \mathrm{~mm}$. L/W ratio $=3.07$. R1 very close to costal vein; vein $R_{2+3}$ arched. Vein Sc apex basal to Rs origin (by distance $1.5 \times$ distance separating $\mathrm{C}, \mathrm{R} 1)$. Ratio $\mathrm{R}_{2+3} /$ $R_{3}$ 0.59. Wing surface covered with microtrichae; veins, margin covered with long setae approximately $59 \mu \mathrm{m}$ in length. Haltere dark brown, length $0.55 \mathrm{~mm}$, knob elongate $114 \mu \mathrm{m} \times 256 \mu \mathrm{m}$.

Legs. All legs setose; hind tibia expanded distally. Foreleg femur, tibia, tarsus lengths 1.26, 1.07, 1.69 $\mathrm{mm}$, respectively. Midleg femur, tibia, tarsus lengths $1.66,1.42,1.78 \mathrm{~mm}$, respectively. Hind leg femur, tibia, tarsus lengths 1.56, 1.58, $2.0 \mathrm{~mm}$, respectively; hind leg claws without apparent teeth (Figure 4.3).

Abdomen and genitalia. Abdomen brown, setose, length $2.84 \mathrm{~mm}$ (including terminalia). Sternite 8 , tergite 9 dark brown/black, more heavily setose. Terminalia width (at widest point of two gonocoxites) $0.419 \mathrm{~mm}$, each gonocoxite approximately $0.202 \mathrm{~mm}$ long and $0.139 \mathrm{~mm}$ wide; gonostylus elongate, length $0.179 \mathrm{~mm}$, width $43 \mu \mathrm{m}$ (Figures $11.1,11.2)$. Gonocoxite apex with possibly two or three spiniform structures, the largest and basalmost $63 \mu \mathrm{m}$ long, $15 \mu \mathrm{m}$ wide at base, not preserved/visible on right gonocoxite. Gonocoxite with large basal lobe, tip spiniform.

Female unknown.

\section{Remarks}

Given the demonstrably unreliable criteria for identification of adult Dixidae at the generic level (see Discussion), the option of designating the four fossil specimens described herein as "Dixidae incertae sedis" was considered. However, given 1) our desire to distinguish these four species from all fossil dixids described previously and 2) the observation that designations such as "Genus incertae sedis" or "Genus indeterminate" are often not recorded in commonly used databases, a generic designation has been provided. The four new species described herein are assigned to the genus Dixella, not necessarily based on morphological criteria, but rather on the near-shore lacustrine environment in which they lived and were deposited (Greenwalt et al., 2015; see Discussion). This 


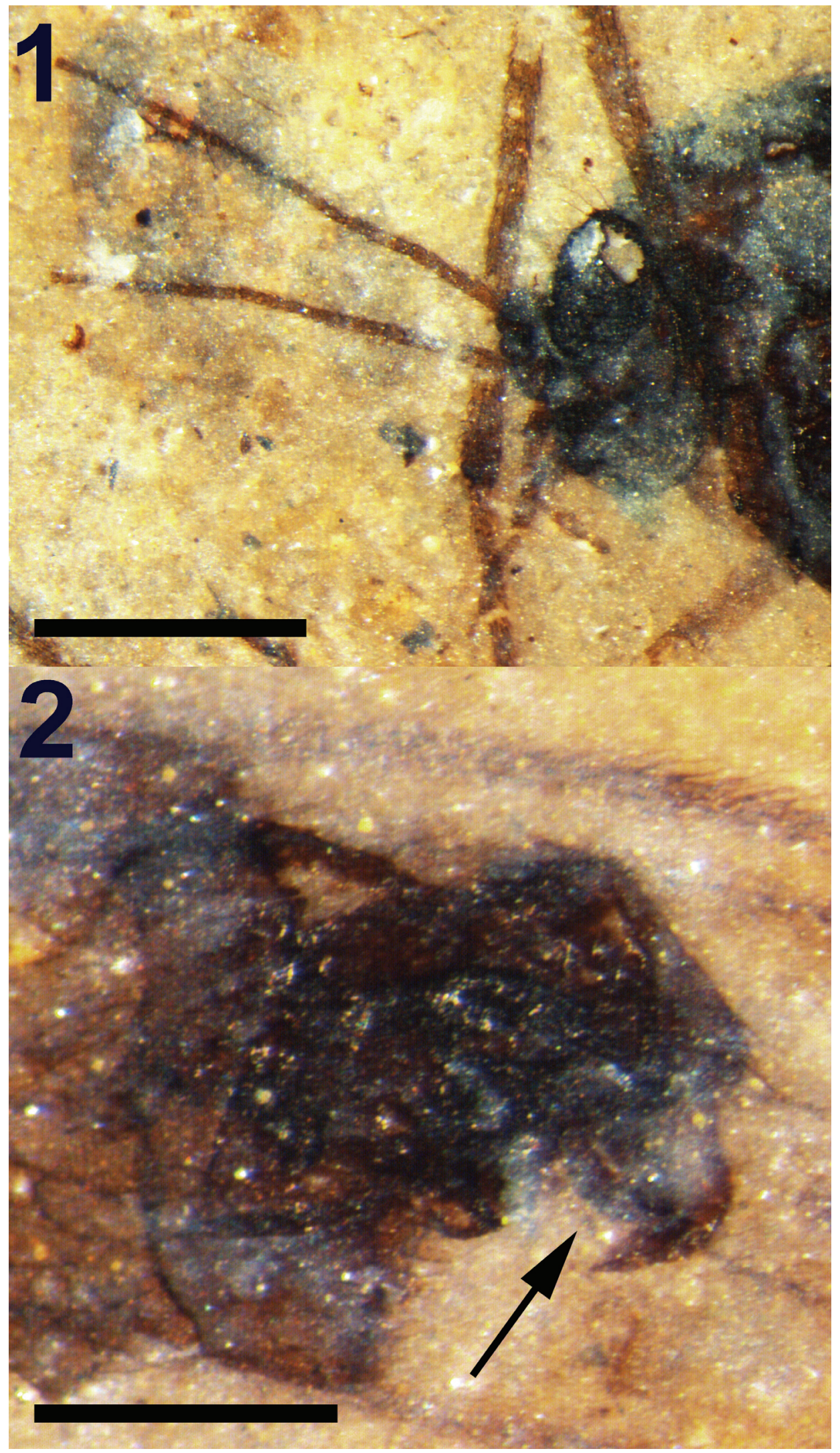

FIGURE 9. Morphological features of Dixella curvistyla. 1, Head and antennae; 2, Terminalia. The arrow points to the apical lobe of the gonocoxite. Scale bars equal $0.5 \mathrm{~mm}(1)$ and $0.2 \mathrm{~mm}(2)$. 


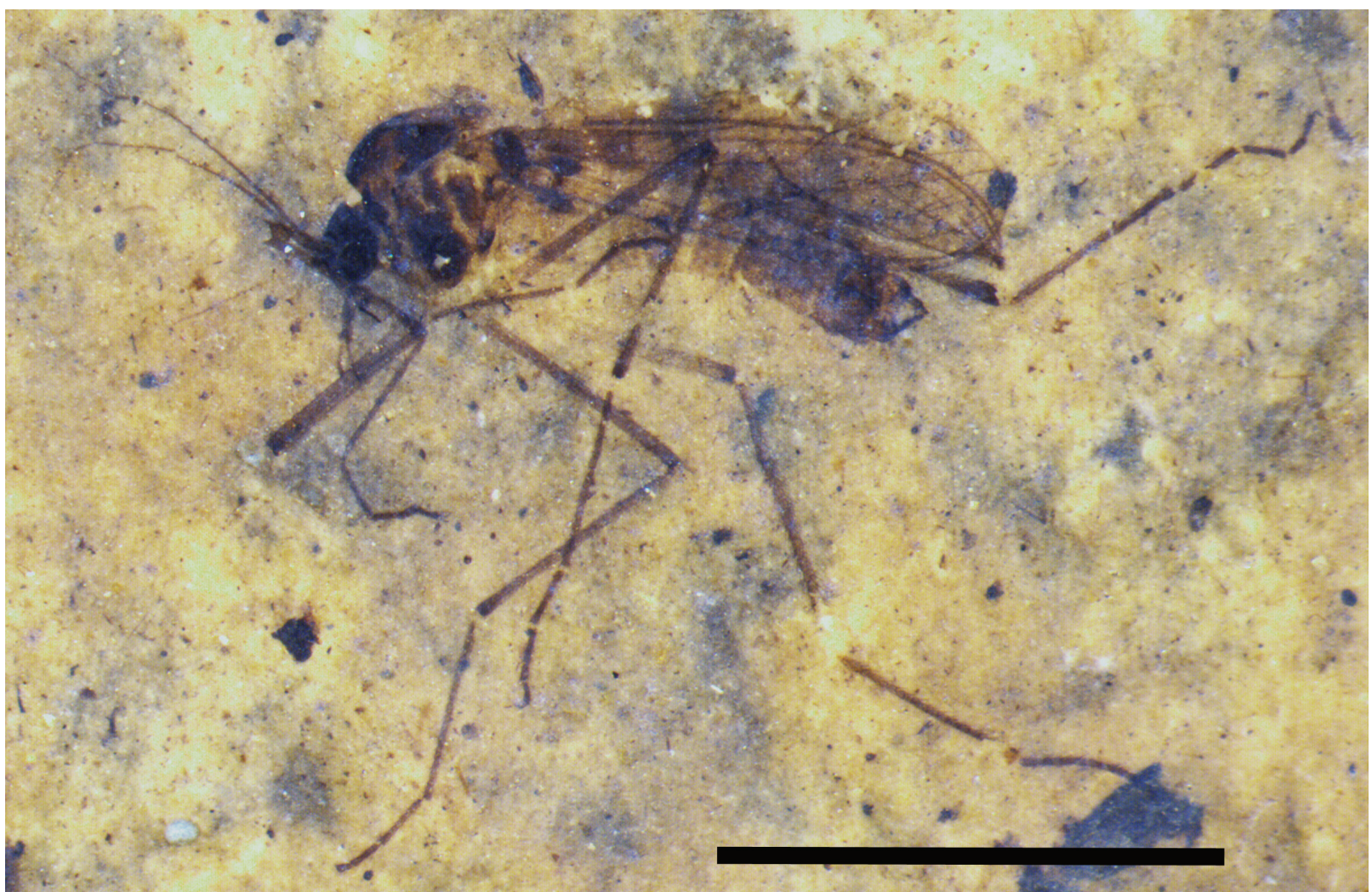

FIGURE 10. Habitus of Dixella spinilobata, holotype. Scale bar equals $3 \mathrm{~mm}$.

of course presumes that genus-specific ecological niches (fast-flowing waters in the mid-stream of waterways or water falls [Dixa] vs. still waters of near-shore lake or pond environments [Dixella] [Nowell, 1951]) had already been established 46 Ma. Specific characteristics, in various combinations, used to distinguish the four fossil Nearctic species from all other dixid genera both extant and extinct, other than Dixa and Dixella, are as follows (with number of species given in parentheses): Syndixa (3): $R_{2}$ fused with $R_{1}$ (Lukashevich, 1996); Eucorethrina (3): $R_{1}$ equidistant from $C$ and $R_{3}\left(R_{2}\right.$ in Peters and Cook [1966]) and Sc ending distad of Rs origin (Lukashevich, 1996); Asiodixa Papp et al., 2006 (2): small size (wings $2.0-2.5 \mathrm{~mm}$ ) and Sc ending substantially before the Rs origin, Rs sigmoidal, F1 of male with a ventromedial dilation (Papp et al., 2006); Neodixa Tonnoir, 1924 (1): $\mathrm{R}_{2+3}$ unbranched (Belkin,1968); Nothodixa (10): first flagellomere oval, its length equal to or less than $2.5 x$ its width (Belkin, 1968); Metadixa Peters and Savary, 1994 (1): known only from a single larval specimen (Peters and Savary, 1994); Mesodixa Belkin et al., 1970 (1): F1 longer than F2 + F3, gonostylus longer than gonocoxite, curved, spinose and small size (wing $2.5 \mathrm{~mm}$ ) (Belkin et al., 1970);
Meringodixa Nowell, 1951 (1): large spatulate ventral process of gonocoxite, F1 fusiform and 6x as long as wide, head and thorax brown and brownish yellow, respectively, stem of haltere yellow and dorsum of abdomen black (Nowell, 1951).

The Cenozoic dixids consist of nine species including the four described herein as well as two designated as incertae sedis (Table 2). A comparison between these is impeded by deficiencies in the published descriptions of the European fossils. Both Dixa priscula and D. cimbrica Ansorge, 1992 were described from isolated wings and, given the variability in wing venation in this family, can only be identified as members of the family Dixidae (see below). Dixa tertiaria Meunier, 1915 was originally described as a member of the family Limoniidae and, although the fossil is of an intact adult, no relevant information was provided other than a very low-resolution photograph and scale bar (Meunier, 1915). Theobald (1937) described Dixa hyalipennis Theobald, 1937 as having venation identical to $D$. tertiaria and synonymized the two species; Evenhuis (1994) synonymized both under $D$. tertiaria. However, comparison of Theobald's figure and Meunier's photograph clearly shows numerous differences in wing venation. Theobald's depiction of 


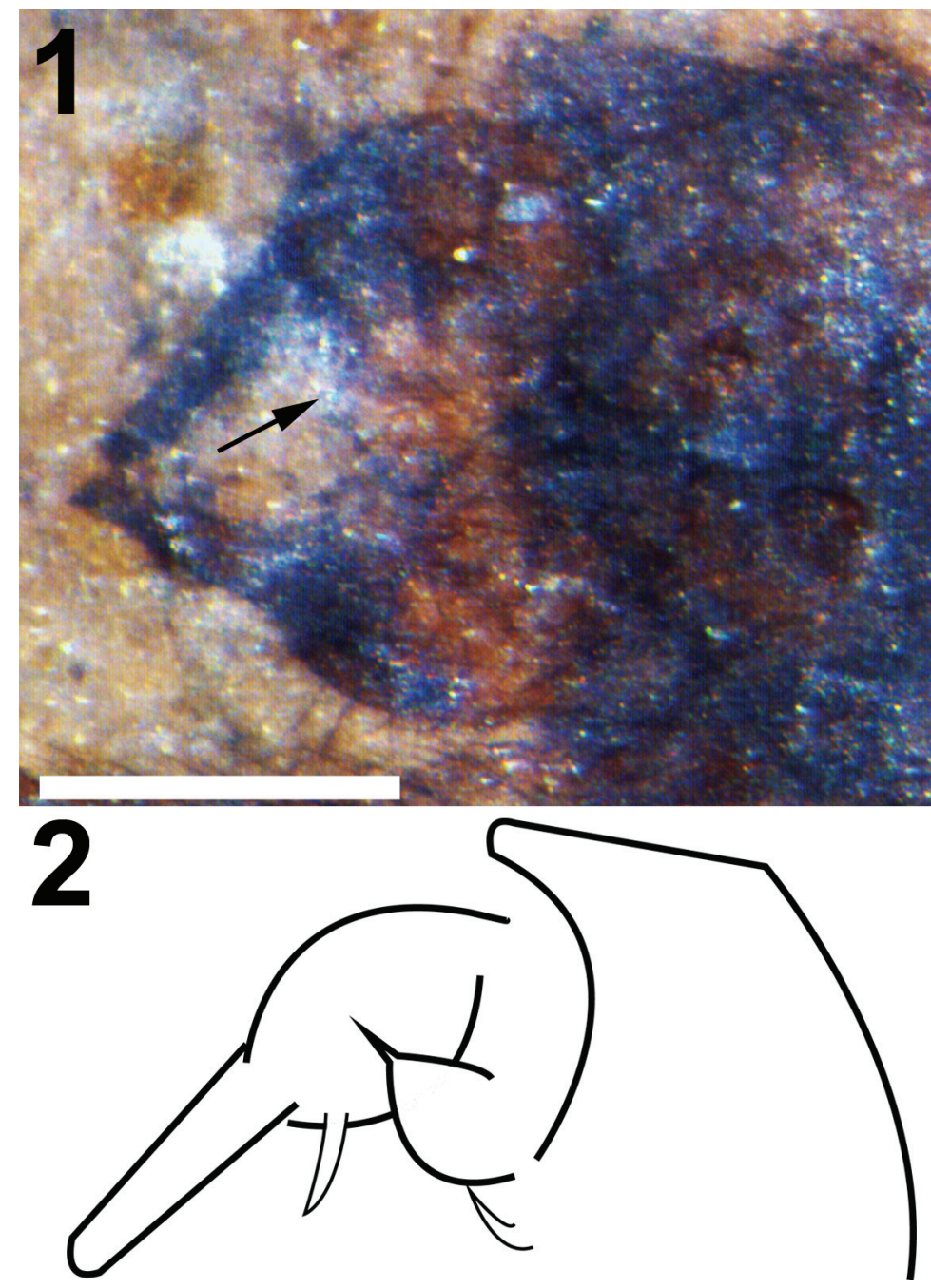

FIGURE 11. Morphological features of Dixella spinilobata. 1, Photograph of the terminalia; spiniform apical lobe marked with an arrow; 2, Line drawing of a partial reconstruction of the right portion of the terminalia (dorsal view). Scale bar equals $0.25 \mathrm{~mm}$.

the first abscissa of CuA1 portrays a vein unlike that in any other species of dixid; the distal half of this vein segment is parallel with vein $M$ and forms a smooth continuous curve with the distal portion of CuA1. Meunier's photograph depicts the first abscissa of $\mathrm{CuA}_{1}$ as straight and at a distinct angle to the second abscissa, in a fashion similar to all other dixids. Descriptions of genitalia are not provided and, in fact, neither specimen is identified as to its sex. Similarly, the genitalia of Dixa succinea were not visible in the original specimen described by Meunier (1906) although it was described as male (mistakenly identified as female in the figure legend). Because the type specimen of Dixa succinea has been lost, Hennig (1966) designated and described a neotype and figured its genitalia as well as those of Dixella filiforceps, $D$. distans and
Dixa minuta Meunier, 1906, all males. Unfortunately, Hennig's descriptions of Dixa succinea, Dixella filiforceps and $D$. distans were otherwise purposefully very brief - no measurements were made - as he believed that "A detailed description of this and the following species would have little meaning. In order to clarify their position within the Paradixinae (Dixella), the extant species must first be carefully worked through."

All four of the Nearctic fossil dixids are distinguished from Dixa minuta and Dixella distans in that these specimens, both Baltic amber inclusions, are much smaller in size with wing widths less than $0.6 \mathrm{~mm}$ (Cockerell, 1921; Hennig, 1966). Although both Dixa priscula and Dixa cimbrica are herein declared nomina dubia (See Discussion), differences in venation between them and the four 
Nearctic fossils are as follows: Dixa cimbrica differs from Dixella eomarginata in that Sc originates at the origin of Rs, Rs forks basal of $r-m$, and m-cu originates basal of $\mathrm{r}-\mathrm{m}$; from Dixella spinilobata in that Sc originates at the origin of Rs; from Dixella curvistyla in that $M_{1+2}$ is longer than $M_{1}$, and $m-c u$ originates basal of $\mathrm{r}-\mathrm{m}$; from Dixella intacta in that $\mathrm{m}$-cu originates basal of $\mathrm{r}-\mathrm{m}$. Dixa priscula differs from Dixella eomarginata in that Sc originates basal of Rs, and $\mathrm{m}$-cu originates basal of $\mathrm{r}-\mathrm{m}$; from Dixella spinilobata in that Sc originates basal of the origin of Rs; from Dixella curvistyla in that $\mathrm{M}_{1+2}$ is longer than $M_{1}, m-c u$ originates basal of $r-m$, and $\mathrm{Sc}$ originates basal of the origin of Rs; from Dixella intacta in that $\mathrm{m}$-cu originates basal of $\mathrm{r}-\mathrm{m}$ and $\mathrm{Sc}$ originates basal of the origin of Rs.

Dixella eomarginata and $D$. intacta differ from all other fossil dixids in being female. Dixella eomarginata differs from all other fossil dixids in having the posterior margin of the wing slightly emarginate between CuA1 and CuA2 - similar to the extant Dixella marginata. The prominent apparent false vein between $M$ and $C u$ that continues between $\mathrm{M}_{1+2}$ and $\mathrm{CuA}_{1}$ in the left wing of $D$. eomarginata may be an artifact, possibly a result of partial delamination of the wing; it does not appear in the right wing. This character is not common in the 'Nematocera' but it is found, between $M_{2}$ and $\mathrm{CuA}_{1}$, in both Scatopsidae (Coboldia Melander, 1916) and several genera of Simuliidae (McAlpine et al., 1981). A false vein parallel to and just posterior of $\mathrm{Cu}$ and $\mathrm{CuA}_{2}$ was described in Dixa appalachiensis (Moulton, 2016). While the male of Dixella marginata lacks the emarginate (excavate) wing margin of the female (Peters and Cook, 1966), there is no evidence for or against Dixella eomarginata being conspecific with either $D$. curvistyla or $D$. spinilobata. The body and wing lengths of Dixella intacta are $34 \%$ and $48 \%$ longer than those of $D$. curvistyla and $29 \%$ longer than $D$. spinilobata, respectively. Males and females of a given species can vary in size, females commonly with larger wing and body lengths, but the relationship is not consistent (e.g., wing lengths in males of both Dixella fraxina Taber, 2010 and D. indiana Dyar, 1925 are often larger than in the female) (Takahasi, 1958; Peters and Cook, 1966; Taber, 2010). Because wing and body lengths within a single sex of a species can vary as much as $50 \%$ (Takahasi, 1958; Peters and Cook, 1966), differences in wing and body lengths alone do not preclude Dixella intacta from a conspecific relationship with $D$. spinilobata or $D$. curvistyla. However, given the absence of any analysis of female genitalia relative to the definition of the genera Dixa and Dixella, the variability in wing venation patterns between these two genera and within individual species (see below and Discussion), and the dearth of morphological detail available for the European fossils, it would be speculative to depict Dixella intacta as congeneric with any other known fossil male dixid.

The male Nearctic fossil species, Dixella curvistyla and $D$. spinilobata, are distinguished from those of $D$. succinea, $D$. filiforceps, and $D$. distans based on the shape of the gonocoxite and gonostylus. The gonocoxite of $D$. succinea is short relative to the gonostylus, the latter tapered distally with the terminal quarter of the stylus bent at a right angle to the base, approximately $150 \mu \mathrm{m}$ long and less than $20 \mu \mathrm{m}$ wide at mid-length. The apical lobe of the gonocoxite is long and narrow (about 75 $\mu \mathrm{m} \times 10 \mu \mathrm{m})$. The gonostylus of $D$. filiforceps is very long and narrow (approximately $225 \mu \mathrm{m}$ long and less than $20 \mu \mathrm{m}$ wide), slightly widened at the end, and smoothly curved such that the distal half is at a right angle to the base. The apical lobe of the gonocoxite is long and narrow (about $10 \mu \mathrm{m} x<$ $10 \mu \mathrm{m})$. The gonocoxite of $D$. distans is short relative to the gonostylus and, like $D$. filiforceps, the gonostylus is long and narrow (approximately 125 $\mu \mathrm{m}$ long $\times 20 \mu \mathrm{m}$ wide) and smoothly curved. Unlike in $D$. filiforceps, the gonostylus is tapered to an asymmetrical point at the end. The apical lobe of the gonocoxite is long and narrow (about $75 \mu \mathrm{m}$ $\mathrm{x}<10 \mu \mathrm{m})$. These characteristics contrast with $D$. curvistyla in which the gonostylus is relatively short and wide (approximately $158 \mu \mathrm{m} \times 79 \mu \mathrm{m}$ at its base) and bent at a near right angle and the apical lobe of the gonocoxite is quite wide (approximately $24 \mu \mathrm{m})$. In contrast, $D$. spinilobata has a straight and relatively wider rectangular gonostylus (179 $\mu \mathrm{m} \times 43 \mu \mathrm{m}$ ) with a relatively shorter apical lobe $(0.35 \times$ the length of the gonostylus vs. ratios of $0.5-0.6$ for the three specimens described by Hennig (1966)).

Dixa tertiaria is problematic in that the original description (Meunier, 1915) is essentially devoid of useful information and no redescription has so far been produced. A photograph and a scale bar is provided and enables body $(3.2 \mathrm{~mm})$ and wing (2.8-3.2 $\mathrm{mm}$ ) lengths to be determined, albeit with a degree of uncertainty. These measurements contrast with those of Theobald (1937), who described Dixa hyalipennis with a body length significantly shorter than the wing length $(3.7 \mathrm{~mm}$ and $4.2 \mathrm{~mm}$ respectively). All of the Nearctic fossils have body/ wing length ratios greater than one. As described above, the very peculiar morphology of vein CuA1, 
as figured by Theobald (1937), also differentiates these two specimens. Without examination of the actual specimens, it is impossible to accurately compare them with the Nearctic dixids.

It is difficult to compare Dixella intacta and $D$. eomarginata with extant dixids of the genera Dixa and Dixella as there exists neither detailed nor extensive studies of female genitalia with respect to the taxonomy of these two genera. Some keys to females of this family exist (e.g., Disney, 1975 which does not use genitalic characters to distinguish between genera) but they are of limited use. The structure of the genitalia of $D$. intacta is very similar to that of Dixa brevis as figured by Nowell (1951). The very broad and acutely curved gonostylus of Dixella curvistyla resembles that of Dixa formosana Papp, 2007 although the latter has a very short apical lobe on the gonocoxite (Papp, 2007). Dixa neohegemonica, with a sickle/fingershaped gonostylal apex, also resembles $D$. curvistyla (Moulton, personal obs.); note that this structure is figured as straight in Peters and Cook (1966). The genitalic morphology of Dixella spinilobata is unique amongst extant members of this family although the gonostylus of Dixa pollex Nowell, 1980 also has a small projection near its distal terminus (Nowell, 1980). A key to all fossils of the family Dixidae, with the exception of Dixa cimbrica, $D$. priscula and $D$. tertiaria, which either consist only of a wing or are too poorly described to provide the data required for inclusion in a key, is provided here so as to facilitate identification of new fossil specimens. below.

See Key to the fossil species of Dixidae

\section{Wing Venation Pattern Variability}

Examination of the 35 different character states for vein position within extant Dixidae reveals that in only 10 instances are specific character states present in one genus and not the other. For example, state " 3 " for the position of the terminus of $A_{1}$ relative to the origin of Rs is not present in extant Dixella. However, this character state exists in extant Dixa in only one of the 50 species examined. In fact, in each of the 10 cases, the character state is rare in the other genus, occurring only once or twice. Therefore, no single character

\section{Key to the fossil species of Dixidae}

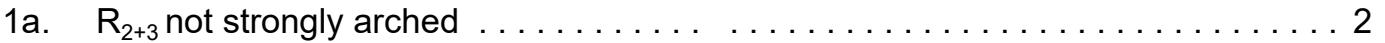

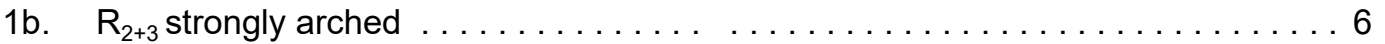

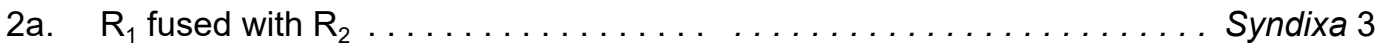

2b. $\quad R_{1}$ not fused with $R_{2} \ldots \ldots \ldots \ldots \ldots \ldots \ldots \ldots \ldots \ldots \ldots \ldots$ Ecothrina 5

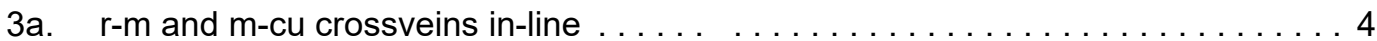

3b. $\quad \mathrm{m}$-cu distal of $\mathrm{r}-\mathrm{m} \ldots \ldots \ldots \ldots \ldots \ldots \ldots \ldots$ Syndixa liasina

4a. $R_{2+3}$ short, $<1 / 4$ length of $R_{2+3}+R_{2} \ldots \ldots \ldots \ldots \ldots \ldots \ldots \ldots \ldots \ldots \ldots \ldots \ldots \ldots \ldots \ldots \ldots$ Sydixa mollis

4b. $\quad R_{2+3}$ subequal to $R_{2} \ldots \ldots \ldots \ldots \ldots \ldots \ldots \ldots \ldots \ldots \ldots \ldots \ldots \ldots$ Sydixa sibirica

5a. Length of Sc relative to wing length $(\mathrm{h}-$ apex $)<0.45 \ldots$ Eucorethrina westwoodi

$5 b$. Length of Sc relative to wing length $(\mathrm{h}-$ apex $)>0.45 \leq 0.50$. . Eucorethrina flexa

$5 \mathrm{c} \quad$ Length of Sc relative to wing length $(\mathrm{h}-$ apex $) \geq 0.50 \ldots$ Eucorethrina convexa

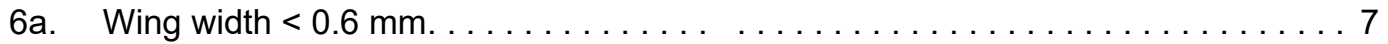

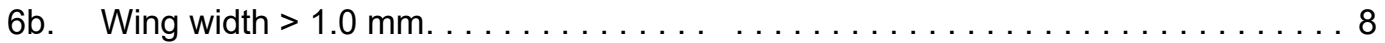

7a. Gonostylus stout, divided apically .... .............. Dixella minuta

7b. Gonostylus long, slender, not divided apically ............. Dixella distans

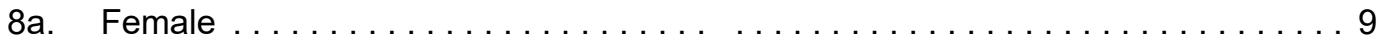

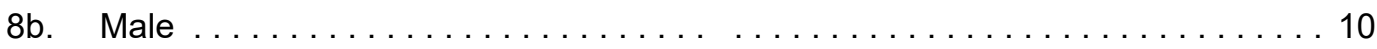

9a. Wing margin emarginated between $\mathrm{CuA}_{1}$ and $\mathrm{CuA}_{2} \ldots \ldots$ Dixella eomarginata

9b. Wing margin not emarginated ...................... Dixella intacta

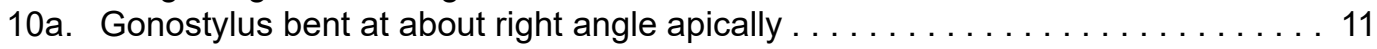

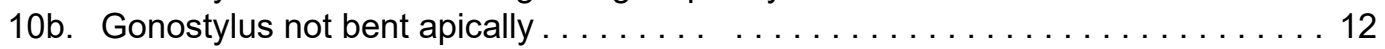

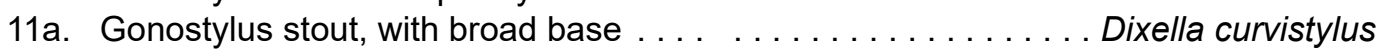

11b. Gonostylus long, slender. . . . . . . . . . . . . . . . . Dixella succinea

12a. Gonostylus moderately long, $\mathrm{L} / \mathrm{W}<5 \ldots \ldots \ldots \ldots \ldots$ Dixella spinilobata

12b. Gonostylus very long, slender, L/W $>10 \ldots \ldots \ldots \ldots \ldots$ Dixella filiforceps 
state is characteristic of (i.e., both universally present in and restricted to) either genus. Similarly, while there are combinations of specific character states that occur in only one of the two genera, they occur only rarely (e.g., the Dixa aliciae Johannsen, 1924 pattern occurs only once within the 50 extant Dixa species examined). There are also instances in which a specific character state or combination of character states is much more likely to occur in one genus. For example, the character state combination $\mathrm{m}-\mathrm{cu} / \mathrm{r}-\mathrm{m}$ as " 4 " and $\mathrm{r}-\mathrm{m} / \mathrm{Rs}$ as " 2 " is 2-fold more common in Dixa than Dixella, but occurs in less than one in four of the Dixa species examined. Similarly the position of the bifurcation of $\mathrm{R} 2+3$ relative to that of $M$ is three times more likely to be "3" or "4" in Dixa than in Dixella, but that combination occurs in a minority of the Dixa species. When the statistically most common combination of character states for each character is calculated for each genus, they are essentially identical: 0, 4/2, 4, 4, 4, 0, 4/0 for Dixa, and 0, 4, 4, 4, 4, 0, 0 for Dixella. Obviously, however, in order for a character state to define a clade, in this case either Dixa or Dixella, that character state must not simply occur once or even statistically most commonly, it must be invariant within that genus. Given these data and the fact that an examination of the holotype of Dixa priscula clearly shows that, in contrast to Cockerell's original description, the crossveins $\mathrm{r}-\mathrm{m}$ and $\mathrm{m}-\mathrm{cu}$ are not preserved, $D$. priscula is reassigned to Dixidae incertae sedis. Similarly, although the venation pattern $(2,4,0,4$, $4,2,0)$ of Dixa cimbrica is unique relative to the 92 species examined in the current study, it too is reassigned to Dixidae incertae sedis.

Figure 12.1-8 depict four examples of intraspecific venation pattern variability. A total of seven different species were examined: photographs of wings from different individuals of Dixa nova Walker, 1848 (Now classified as Dixella [Pape and Thompson, 2013]), Dixa terna Loew, 1863, D. rhathyme Dyar and Shannon, 1924 and Dixella obscura Loew, 1849, for which 16, 14, seven and four specimens were examined, respectively, are shown. Dixella torrentia Lane, 1939 and D. solomonis Belkin, 1962, for which six and seven specimens were examined, respectively, displayed variability but to a degree less than that found in the figured species. Dixella cornuta Johannsen, 1923, for which only six specimens were examined, exhibited no variability. For four of the seven species examined, all specimens were from the same locality. Specimens of Dixa terna were from Pennsylvania and Virginia, Dixella obscura from
Arizona and Alaska and Dixella cornuta from Delaware and Idaho. In all four figured species, the relative position of the crossvein $r-m$ varies from even (2) to apical (4) of the Rs fork. The relative position of Sc differs in two of the four figured species, ranging from even to basal relative to the origin of Rs in Dixella obscura and from apical to basal in Dixa rhathyme. The position of $\mathrm{m}-\mathrm{cu}$ relative to $\mathrm{r}-\mathrm{m}$ is apical in one of the two specimens of Dixella obscura and basal in the other.

\section{DISCUSSION}

The current unsatisfactory state of dixid taxonomy appears to be due to several factors: 1) as Belkin (1968) states, "Speciation has been accompanied by very few and minor changes in the general external characters of the adults.", 2) a large degree of both interspecific and intraspecific variability (Peus, 1936; Peters and Cook, 1966; Disney, 1975), and 3) choices of seemingly superficial criteria for the definition of genera (Takahashi, 1958; Hennig, 1966; Borkent, 2009). As a result, the generic assignment of fossil species within the family Dixidae is a challenge. Several keys to extant dixids exist but they are geographically restricted, out-of-date, or both (Nowell, 1951; Takahashi, 1958; Peters and Cook, 1966; Nowell, 1980). The Nearctic species were last treated by Peters and Cook (1966); dixids of Asia were keyed by Nowell (1980), although the 10 species from Japan described by Takahashi (1958) were not included. Numerous species of this family have been described from the tropics of both America and Asia in the last decade and we can assume that many more await discovery (Papp et al., 2006; Chaverrl and Borkent, 2007; Papp, 2007; Taber, 2010). The most robust morphological characters for differentiation between Dixa and Dixella appear to be those of the larval stage (Nowell, 1951; Belkin, 1968; Disney, 1975), and keys have been devised that separate these genera based on character states of the immature stages (Edwards, 1932; Johannsen, 1933; Smith, 1938; Belkin, 1968; Disney, 1975). The necessity to identify the dixid imago has led to a reliance on what has been termed uninformative characters (Takahasi, 1958; Belkin, 1968); their weaknesses in generic and suprageneric classification, as used in the literature, are discussed in detail here.

Tonnoir (1924), in his original differentiation of Dixa and Paradixa Tonnoir, 1924 (now Dixella), defined Paradixa, in part, as having crossvein r-m at or distal to the fork of Rs. However, as long ago as 1923, Johannsen described intraspecific varia- 

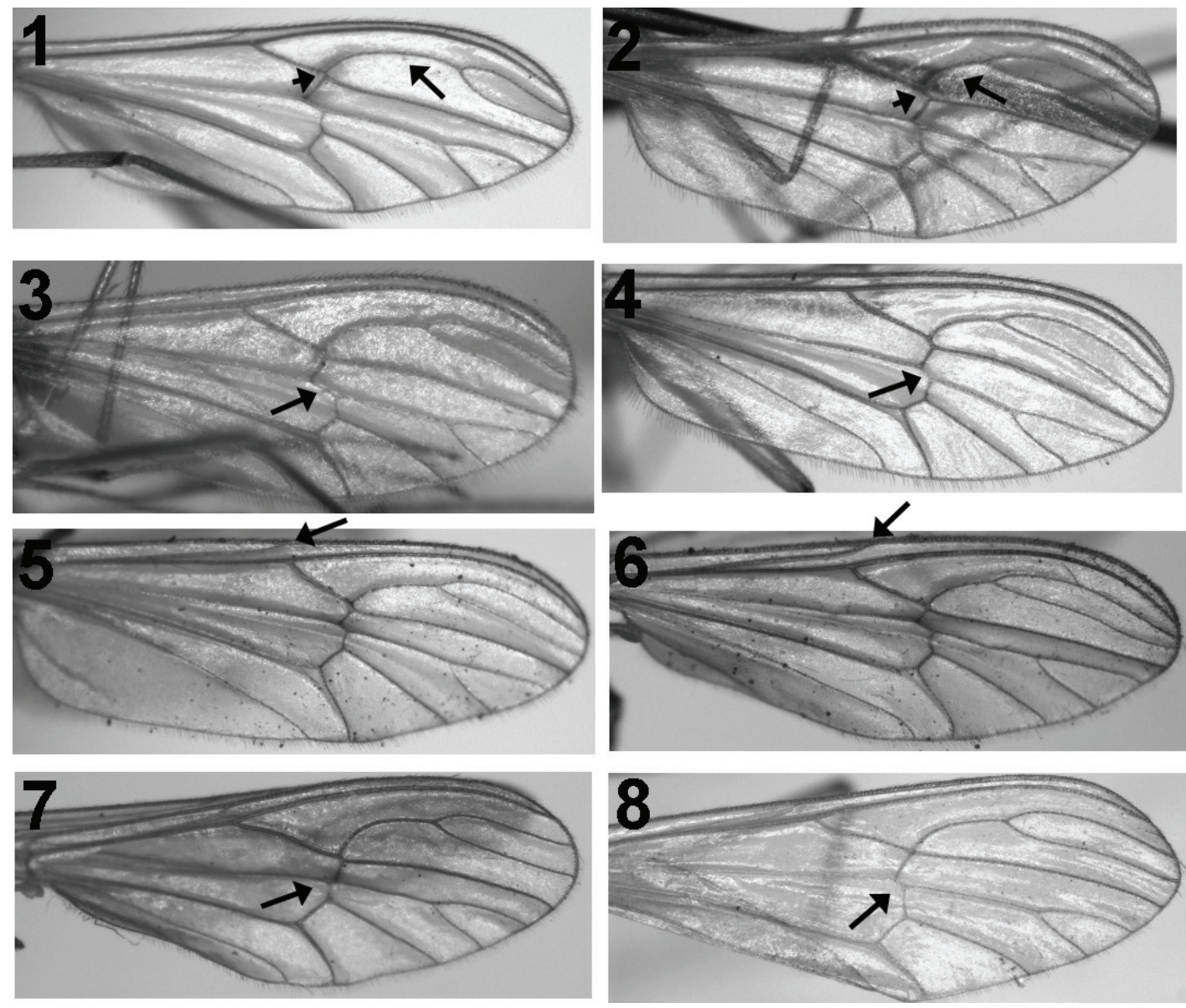

FIGURE 12. Intraspecific wing venation pattern variability in Dixidae. 1-2, Wings from two different individuals of Dixella nova (USNM01193745, USNM01193785, ㅇ, ô, respectively; NY). 3-4, Wings from two different individuals of Dixa terna (USNM01193791, USNM01193792, $\hat{\jmath}$, $\hat{0}$, respectively; PA \& VA). 5-6, Wings from two different individuals of Dixa rhathyme (USNM01193798, USNM01193868, ?, , , respectively; CA). 7-8, Wings from two different individuals of Dixella obscura (USNM01193908, USNM01193974, ?, , , respectively; AZ \& AK). Collection localities are in parentheses. Arrows and arrowheads denote specific points of variation. Abbreviations: $A K=$ Alaska, $A Z=A r i z o n a, C A=C a l i-$ fornia, NY = New York, PA = Pennsylvania, VA = Virginia, USA.

bility in the wing venation of two species of dixids. Peus (1936) also detailed significant variation in the wing venation patterns of members of this family. Locality-specific differences in the position of crossvein $\mathrm{m}$-cu were noted in Dixa pyrenaica Seguy, 1921 (Now classified as Dixella [Pape and Thompson, 2013]), and differences in the positions of both $\mathrm{m}$-cu and $\mathrm{r}-\mathrm{m}$ were documented in specimens of Dixa laeta Loew, 1849 (Now classified as Dixella [Pape and Thompson, 2013]), from the same locality; minor differences were found in the two wings of a single specimen. Variability in the venation pattern of Dixa filicornis Edwards, 1926 (Now classified as Dixella [Pape and Thompson, 2013]), was also observed. Peus (1936) concluded that wing veins were "wertlos und unbrauchbar" (worthless and unusable) in species-level identifications. This may be an overstatement, however, as not all dixid species exhibit the same degree of variability. Nevertheless, Disney (1975) documented intraspecific variability in venation patterns in Dixella attica Pandazis, 1933 and D. autumnalis Meigen, 1838 with, for example, crossvein r-m basad of the bifurcation of Rs in one individual and apical in another. Disney, like Peus, also demonstrated variability in wings from the same individual. In Peters and Cook's (1966) revision of the Nearctic Dixidae, 23 species of Dixa and 18 species of Dixella were examined. Although the positions of the various veins were not extensively studied, their lengths were. In three of 23 Dixa species, the length of $R_{2+3}$ varied by a factor greater 
than 2 amongst individuals of the same species. Such huge intraspecific differences were also found in one species of Dixella. The length of $\mathrm{M}_{3+4}$ varied by more than twofold within several other species of Dixella; differences of $\pm 25 \%$ were common.

Statements by Cockerell (1921) that Dixa priscula's "venation is typical for Dixa," Ansorge (1992) that "Typical Dixidae (with) m-cu crossvein located proximal to the r-m crossvein" and Hennig (1966) that "the location (basal to the bifurcation of Rs) of the crossvein r-m of (Dixa) minuta is not an entirely random feature," are inaccurate. Although Cockerell's statement must be taken in historical context - Nothodixa was the only genus other than Dixa recognized in 1921, the point is that Dixa- and Dixella-specific venation patterns do not appear to exist. In contrast to the statements of Ansorge and Hennig, r-m basal to the bifurcation of Rs is more than twice as likely to occur in Dixella than Dixa and $\mathrm{m}$-cu basal to $\mathrm{r}-\mathrm{m}$ was found in only $11.5 \%$ of the Dixa and Dixella species examined in the present study. The data from the comparative study reported here demonstrate that there is no single wing venation character or combination of characters that is unique to either genus (Appendix 3). The very small numbers of specimens that had to be examined in order to establish even intraspecific pattern variation underlines the predominance of this phenomenon. Given these data and the fact that an examination of the holotype of Dixa priscula clearly shows that, in contrast to Cockerell's original description, the crossveins $r-m$ and $m-c u$ are not preserved, $D$. priscula is reassigned to Dixidae incertae sedis. Similarly, although the venation pattern of Dixa cimbrica (2, 4, 0, 4, 4, 2, 0 [Appendix $3])$ is unique relative to those examined in the current study, it too can not be assigned to genus and is reassigned to Dixidae incertae sedis.

Although these data were not generated by a formal cladistic study, they provide conclusive documentation of the symplesiomorphic nature of venation-based character states within the genera Dixa and Dixella. These data then form the basis of our conclusion that generic assignments cannot be made on venation-based character states. The comprehensive cladistic analysis required to establish or reject the validity of these two genera, while beyond the scope of the current study, is essential to our understanding of the organization of the family. If character states that accurately define genera within the family can be established, the question of the utility of wing venation patterns at the generic level will have to be reexamined.
Use of the size and form of the antennae was introduced by Tonnoir (1924) and Garrett (1924) and persists today in differentiation of the two major genera, Dixa and Dixella; species of Dixa are usually described as having a fusiform first flagellomere (F1) while those of Dixella have a cylindrical F1. However, published descriptions, in reference to both F1 and all flagellomeres, differ substantially, as exemplified by the following examples. For Dixa: "flagellar segments distinct," F1 "fusiform, much thicker medially than basally or apically," F1 "slightly fusiform"; F1 "swollen while the other basal segments . . . at least slightly fusiform if not swollen," F1 "cylindrical, slightly fusiform," F1 "terete" (cylindrical, tapering at both ends), "flagellar segments narrow and cylindrical" (subgenus Dixella sensu Nowell, 1980), F1 "somewhat fusiform (i.e., not strictly cylindrical)." For Dixella: F1 "cylindrical, rarely slightly fusiform," "flagellar segments all elongate, cylindrical," F1 "elongate, cylindrical and no segments fusiform," "all segments of flagellum elongated, filiform and scarcely distinguishable from one another," F1 "elongate fusiform rather than strictly cylindrical" (Dixella sensu Nowell, 1951), F1 "slightly fusiform so that flagellar segments are distinct" (Nowell, 1951; Peters and Cook, 1966; Belkin, 1968; Disney, 1975; Nowell, 1980; Peters, 1992, 1993; Papp, 2007). Difficulty in interpretation of this character state has led to its abandonment by some authors. Takahashi (1958) identified 10 new species of the genus Dixa, four of which were described as having F1 cylindrical. In the same study, the F1 of Dixella subobscura Takahashi, 1958 was described as "somewhat widened before the middle."

The ratio of $\mathrm{F} 1$ length/width and the total length of the antenna have also been widely used. For example, Nowell (1951) described Dixa with F1 "about three to four times as long as broad, rarely less or more" and Paradixa and Dixella (both now as Dixella) with F1 "at least five times as long as broad" or "about six times as broad," respectively. In his key to Oriental species, Nowell (1980) described Dixa with F1 four to six times as long as broad and three species that are currently classified as Dixella as having F1 10 to 15 times as along as broad. Takahashi (1958) described 10 species of Dixa with F1 length/width ratios of 4.5 to $10(6 / 10$ with the ratio $\geq 7)$ and a ratio of about 5 for Dixella subobscura. Chaverri and Borkent (2007) recently described 10 new species of Dixella and, in the six species for which measurement could be made (from figure 1), the F1 length to width ratio 
varied from 6.75 to 9.1. Peters (1993) described Dixa dolichostyla Peters, 1993 with a F1 length/ width ratio of 8, while Papp (2007) described Dixa foldvarii Papp, 2007 with this ratio equal to 7.5 to 8 and "i.e., between the realms of Dixa and Dixella." Takahashi concluded that this particular "character does not divide accurately the (Dixa and Dixella) groups." Similarly, the total lengths of the antennae have failed to enable a clear discrimination between Dixa and Dixella. Nowell (1951) described Dixa as having "antennae moderately long, scarcely longer than the thorax" and Paradixa with elongate antennae or antennae "nearly as long as the body." Belkin (1968), in a key to the Culicoidea of New Zealand, characterized the antennae of Paradixa as 1.5 times as long as the head and thorax combined. Peters and Cook (1966) described Dixella indiana with antennae about $2 / 3$ the length of the wing (total body lengths were not provided) and later, Peters (1993) described Dixa dolichostyla as having antennae 2.3 times the length of the thorax. When applied to Dixella intacta, the criteria provided in the three preceding studies give antenna/body length ratios of $0.52,0.65$ and 0.65 , respectively. It appears that, within Dixidae, F1 and total antennal length and flagellomere shape are both continua with no defining boundaries.

Details of the structure of pretarsal claws have also been used in the classification of the Dixidae (Nowell, 1951; Peters and Cook, 1966; Belkin, 1968; Belkin et al., 1970; Peters, 1981, 1993; Chaverri and Borkent, 2007; Tabor, 2010). Numerous studies have documented sexual dimorphism relative to claw structure; pretarsal claws of females are smaller than those of males and have basal combs composed of variable numbers of short and/or long teeth as well as what has been termed spicules on the lateral surfaces of the claws. The pretarsal claws of males have basal combs that are often smaller than those of females, as well as external spicules. Unique to the pretarsal claws of males, however, are teeth, sometimes described as pectinate, on the venter or ventral (concave) surface of the claw. These ventral teeth have been reported to vary in number from zero to as many as seven per claw. The pretarsal claws of both males and females of the genera Dixa, Mesodixa, Nothodixa, and Dixella have been figured in several studies (Nowell, 1951; Belkin, 1968; Belkin et al., 1970; Chaverri and Borkent, 2007; Tabor, 2010). Nowell (1951) described male Dixa as with long fine teeth on fore- and midpretarsal claws and male Dixella as with short fine teeth on all legs. Peters and Cook (1966) later described Dixa with hind leg pretarsal claws of males frequently without ventral teeth and male Dixella hind leg tarsi as frequently with ventral teeth. Peter and Cook's key twice used the symbol $q$ in describing pretarsal claws where $\delta$ was intended (key to genera, couplets 1 and 2). Of the 20 species of Dixa for which they described the hind leg pretarsal claws, three species were described as having "very small", "short, weak," or "moderately long" ventral teeth and three species had "long ventral teeth"; in the remaining 16 species, the metatarsal claws were "simple" (without teeth). Of the 15 species of Dixella for which descriptions of the hind leg pretarsal claws were given, three species had simple claws and a fourth was without "prominent teeth." Peters (1981) amended his description of Dixa to hind leg pretarsal claws \pm ventral teeth and in 1993, described Dixa dolichostyla as having four long teeth on the pro- and middle leg tarsi but only "with a few weak hairs" on the ventral aspect of the hind leg pretarsal claws. Belkin (1968) described the genus Nothodixa with all claws pectinate (4-5 teeth per claw) and the genus Dixella (with four species in New Zealand) with pro- and middle leg pretarsal claws pectinate but the hind leg tarsal claw either simple or with a single tooth. He figured Dixella neozelandica Tonnoir, 1924 with 4, 2, and 1 teeth on the pro-, meso-, and hind leg pretarsal claws, respectively. Belkin et al. (1970) described the male of Mesodixa biambulacra Belkin, Heinemann, and Page, 1970 with four to five teeth on all pretarsal claws and the male of Dixella scitula Belkin, Heinemann and Page, 1970 with three to four moderately long teeth on all legs. Peters (1992) described a specimen of Dixa orientalae Peters, 1992 with three to four hind leg pretarsal teeth. More recently, Chaverri and Borkent (2007) figured the pretarsal claws of the males of 10 species of Dixella and depicted metatarsal claws with from zero to as many as three ventral teeth. In some species, the teeth do not originate strictly ventrally but subventrally/laterally and, in such cases are usually smaller in diameter. Dixella jironi Chaverri and Borkent, 2007 has a single short tooth at the distal base of the claw but the ventral aspect of the claw itself has no teeth. This same study also documented significant variation in the number of teeth on the two claws of a single pretarsus. Taber (2010) figured Dixella fraxina with five long ventral teeth on all pretarsi of the male. It appears obvious that, while there may be a tendency towards fewer hind leg pretarsal ventral teeth in male Dixa relative to Dixella, the relationship is not invariant and does not provide an accurate basis for classification. 
In his generic and suprageneric keys, Nowell (1951) did not utilize genitalic features. However, in descriptions of individual genera, species of Dixa were characterized as either without an apical lobe of the gonocoxite or with a short apical lobe, Nothodixa as without a prominent apical lobe, Paradixa as with a long apical lobe "usually half as long as the style or longer" and Dixella with a "moderately long apical (lobe)." Peters' (1981) key characterized Dixella as with an apical lobe greater or equal to the length of the gonostylus and Dixa as with an apical lobe less than half the length of the gonostylus. Numerous additional descriptions of species of Dixa and Dixella suggest that the relative lengths of the apical lobe of the gonocoxite and the gonostylus accurately define the two genera (Belkin et al., 1970; Nowell, 1980; Peters, 1993; Chaverri and Borkent, 2007; Papp, 2007). However, exceptions have been reported. Belkin (1968) described three species of Dixella (D. harrisi Tonnoir, 1925, $D$. neozelandica, and $D$. fuscinervis Tonnoir, 1924) as having "short" or "very short" apical lobes with lengths less than half that of the gonostylus. Disney (1975) described Dixella corensis Peters, 1992 with an apical lobe less than half the length of the gonostylus. Of the 11 species described by Takahasi (1958), there was a single exception, Dixa longistyla Takahashi, 1958, which was described with a "dorsal process relatively long." Peus (1936) figured both Dixa borealis Martini, 1929 and $D$. pyrenaica with apical lobes greater than half the length of the gonostylus. Dixa pyrenaica, however, was subsequently synonymized with Dixella obscura (Pape and Thompson, 2013). Tabor (2010) described Dixella fraxina with "the digitate extension of the apical lobe less than half the length of the (gonostyle)." However, if the length is taken from the base of the lobe, the apical lobe of $D$. fraxina is greater than that of the gonostylus. Belkin (1968), in reviewing the morphology of the male genitalia, stated that the "superficial details of . . . the sidepiece (gonocoxite) and clasper (gonostylus) ... show excellent diagnostic features" but this at the species level. Disney (1975), in describing the British Dixidae, reared each of the 14 endemic species and produced keys for both male and female imago, the larvae and the pupae. In his key, the primary character used in the differentiation of the male adults (six Dixa and eight Dixella) was the length of the apical lobe of the gonocoxite relative to that of the gonostylus. However, the variability cited in the discussion above suggests that, until the exceptions described in the literature are re-examined and many other species in both Dixa and Dixella are are reared, Disney's limited study cannot be extrapolated to the genera of the world.

Individual character states based on wing venation and antennal, genital and metapretarsal morphology are homoplastic and do not separate the dixids into natural divisions. Hennig (1966) voiced similar concerns, purposefully limiting his descriptions of Dixa succinea, Dixella filiforceps and $D$. distans. Takahasi (1958) referred to his key to the Dixidae of Japan as "artificial." Despite welldocumented variability in all of the adult characters used to define Dixa and Dixella and the numerous admonitions by essentially all of the leading dixid taxonomists that these two genera are problematic, the designation of new species, in the absence of study of both larvae and adult specimens, continues. It should be noted that Takahashi's Dixa obtusa Takahashi, 1958 should be placed in the genus Dixella (T. Saigusa, unpublished observations) based on larval morphology; this same observation is supported by molecular data (J.K. Moulton, unpublished data). The morphology of immature stages has been described by a number of investigators, but the number of species involved is very limited (Edwards, 1932; Johannsen, 1933; Smith, 1938; Nowell, 1951; Belkin, 1962, 1968; Brundin, 1966; Belkin et al., 1970; Disney, 1975; Borkent, 2012). For example, Borkent (2012), in a search of the literature for detailed descriptions of dixid pupae, found only seven, only one of which was genus Dixa. Larval and/or pupal synapomorphies specific to redefined Dixa and Dixella, should be a major thrust of future morphology-based research. The two major genera within Dixidae, as currently defined in the literature, are obviously not monophyletic. Detailed cladistic analyses that utilize both morphological and molecular data, along with expanded studies of larval and pupal morphology, are required to establish whether or not any natural monophyletic subdivisions exist within the family.

Nowell (1951) recognized that the major genera Dixa and Dixella could be differentiated based on their respective habitat: Dixa, never found in quiet pools of water, preferring the fast flowing water of the middle of streams and waterfalls and Dixella, found in both the quiet waters of ponds and lake edges as well as fast-flowing streams. Nowell qualified the latter, however, in stating that when Dixella reside in streams and rivers, they are at the water line (e.g., moving up and down on vegetation). Håland (2009) reported a rare exception with the collection of a single specimen of Dixa nebu- 
losa Meigen, 1830 from a small lake. In reality this habitat distinction is not clear-cut. For instance, Dixa fluvica prefers slow flowing watercresschoked springs (almost ditches) and Dixella cornuta and Dixa pseudindiana occur in streams and rivers, respectively (Moulton, personal obs.). Although the four new fossil species of Dixella were collected at three different sites, all of the sites had shallow near-shore depositional environments (Greenwalt et al., 2015).

Fossil Dixidae are essential tools in our understanding of the phylogeny and evolution of this and related families. Other fossil Dixidae await description. Grimaldi and Engel (2005) and Haenni (2003) have reported specimens in Eocene Baltic amber and Dixidae in Miocene Dominican and Eocene Rovno amber have also been reported (Poinar, 1992; Perkovsky et al., 2010). Meniscus midges have also been reported from the Eocene Fossil Butte Member of the Green River Formation (Grande, 2013). A single specimen of an adult dixid has been reported from the Cretaceous Koonwarra fossil bed in Victoria, Australia (Jell and Duncan, 1986). Description of this latter specimen is of particular interest given that all described fossil Dixidae are from the Holarctic region. The Koonwarra bed has been dated to $116 \pm 5 \mathrm{Ma}$ (Drinnan and Chambers, 1986) so it would be of interest to compare and contrast the Australian dixid with the only other fossil dixid from the Cretaceous, Eucorethrina westwoodi.

\section{ACKNOWLEDGEMENTS}

We thank C. Labandeira (Dept. of Paleobiology, NMNH) for sponsorship and administrative support and F. Marsh (Dept. of Paleobiology, $\mathrm{NMNH}$ ) for his ongoing assistance. We also thank J. Pecor of the Walter Reed Biosystematics unit located in the Smithsonian Institution's MSC in Suitland, MD, and C. Mellish of the Earth Sciences Department of the NHM, London for access to specimens. We also wish to thank an anonymous reviewer and $\mathrm{A}$. Borkent and $\mathrm{S}$. Brady for numerous and insightful comments that led to significant improvements in the manuscript. This is contribution number 277 of the Evolution of Terrestrial Ecosystems Consortium of the National Museum of Natural History in Washington, D.C.

\section{REFERENCES}

Ansorge, J. 1992. Dixa cimbrica n. sp., ein Vertreter der Dixidae (Diptera, Nematocera) aus der oberpaleozänen/untereozänen Fur-Formation (Moler) Jütlands
(Dänemark). Neues Jahrbuch für Geologie und Paläontologie, Monatshefte, 9:513-518.

Belkin, J.N. 1962. The mosquitoes of the South Pacific (Diptera: Culicidae), Vol. II. University of California Press, Berkeley, CA.

Belkin, J.N. 1968. The Culicidae of New Zealand. American Entomological Institute, Contributions, 3:1-182.

Belkin, J.N., Heinemann, S.J., and Page, W.A. 1970. The Culicidae of Jamaica (Mosquito studies. XXI). American Entomological Institute, Contributions, 6:1458.

Bertone, M.A., Courtney, G.W., and Wiegmann, B.M. 2008. Phylogenetics and temporal diversification of the earliest true flies (Insects: Diptera) based on multiple nuclear genes. Systematic Entomology, 33:668687.

Blagoderov, V., Grimaldi, D.A., and Fraser, N.C. 2007. How time flies for flies: Diverse Diptera from the Triassic of Virginia and early radiation of the order. American Museum Novitates, 3572:1-39.

Borkent, A. 2009. Dixidae (Meniscus Midges), p. 359360. In Brown, B.V., Borkent, A., Cumming, J.M., Wood, D.M., Woodley, N.E., and Zumbado, M.A. (eds.), Manual of Central American Diptera. NRC Research Press, Ottawa, CA.

Borkent, A. 2012. The pupae of Culicomorpha - morphology and a new phylogenetic tree. Zootaxa, 3396:1-98.

Brundin, L. 1966. Transantarctic relationships and their significance, as evidenced by chironomid midges. Swenska Wetenskaps Academiens Handligar, 11:1472.

Chaverri, L.G. and Borkent, A. 2007. The meniscus midges of Costa Rica (Diptera: Dixidae). Zootaxa, 1575:1-34.

Cockerell, T.D.A. 1921. Fossil arthropods in the British Museum. VI. Oligocene insects from Gurnet Bay, Isle of Wight. The Annals and Magazine of Natural History (ninth series; No. 42), 7:453-479.

Constenius, K. 1996. Late Paleogene extensional collapse of the Cordilleran foreland fold and thrust belt. Geological Society of America Bulletin, 108:20-39.

Constenius, K., Dawson, M.R., Pierce, H.G., Walter, R.C., and Wilson, M.V.H. 1989. Reconnaissance paleontologic study of the Kishenehn Formation, northwestern Montana and southeastern British Columbia. Field Conference Guidebook. Geological Resources of Montana, 1:189-203.

Disney, R.H.L. 1975. A key to the larvae, pupae and adults of the British Dixidae (Diptera). Scientific Publication No. 31, Freshwater Biological Association, Ambleside, UK.

Drinnan, A.N. and Chambers, C. 1986. Flora of the Lower Cretaceous, Koonwarra fossil bed (Korumburra Group), South Gippsland, Victoria, p. 1-77. In Jell, P.A. and Roberts J. (eds.), Plants and invertebrates from the Lower Cretaceous Koonwarra fossil bed, South Gippsland, Victoria. Memoir 3 of the Association of Australian Paleontologists, Sydney. 
Dyar, H. G. 1925. A new North American Dixa and note (Diptera, Culicidae). Insecutor inscitiae menstruus, 13:217-218.

Dyar, H.G. and Shannon, R.C. 1924. Some new species of American Dixa Meigen. Insecutor Inscitiae Menstruus, 12:193-201.

Edwards, F.W. 1926. A new species of Dixa from Sussex (Diptera Culicidae). Entomologist's Monthly Magazine, 62:35.

Edwards, F.W. 1930. Bibionidae, Scatopsidae, Cecidomyiidae, Culicidae, Thaumaleidae (Orphnephilidae), Anisopodidae (Rhyphidae). Dipt. Patagonia S. Chile, 2:77-119.

Edwards, F.W. 1932. Diptera Family Culicidae. Genera Insectorum, 194:1-258.

Evenhuis, N.L. 1994. Catalogue of the fossil flies of the world (Insects: Diptera). Backhuys Publishers, Leiden.

Felt, E.P. 1904. Mosquitos or Culicidae of New York State. New York State Museum, Bulletin 79, Entomology, 22:241-400.

Garrett, C.B.D. 1924. New American Dixidae. Cranbrook Courier, British Columbia.

Grande, L. 2013. The lost world of Fossil Lake: Snapshots from deep time. The University of Chicago Press, Chicago.

Greenwalt, D.E., Rose, T.R., Siljeström, S.M., Goreva, Y.S., Constenius, K.N., and Wingerath, J.G. 2015. Taphonomic studies of the fossil insects of the Middle Eocene Kishenehn Formation. Acta Palaeontologica Polonica, 60(4):931-947.

Grimaldi, D.A. and Engel, M.S. 2005. Evolution of the Insects. Cambridge University Press, New York.

Haenni, J.P. 2003. Fossil Diptera in Baltic amber: the collection of the Muséum d'histoire naturelle Neuchâtel. Acta zoologica cracoviensia, 46:407-410.

Håland, $\varnothing$. 2009. Notes on the life cycles of Norwegian Dixella species (Diptera, Nematocera, Dixidae). Norwegian Journal of Entomology, 56:37-43.

Harbach, R.E. and Greenwalt, D. 2012. Two Eocene species of Culiseta (Diptera: Culicidae) from the Kishenehn Formation in Montana. Zootaxa, 3530:2534.

Hennig, W. 1966. Dixidae aus dem Baltischen Bernstein, mit Bemerkungen uber einige andere fossile Arten aus der Gruppe Culicoidea (Diptera: Nematocera). Stuttgarter Beiträge zur Naturkunde, 153:1-16.

Huber, J.T. and Greenwalt, D. 2011. Compression fossil Mymaridae (Hymenoptera) from Kishenehn oil shales, with description of two new genera and review of Tertiary amber genera. Zookeys, 130:473494.

Jell, P.A. and Duncan, P.M. 1986. Invertebrates, mainly insects, from the freshwater, Lower Cretaceous, Koonwarra fossil bed (Korumburra Group), South Gippsland, Victoria, p. 111-205. In Jell, P.A. and Roberts J. (eds.), Plants and invertebrates from the Lower Cretaceous Koonwarra fossil bed, South
Gippsland, Victoria. Memoir 3 of the Association of Australian Paleontologists, Sydney.

Johannsen, O.A. 1923. North American Dixidae. Psyche, 30:52-58.

Johannsen, O.A. 1924. A new species of Dixa from California. Psyche, 31:45-48.

Johannsen, O.A. 1933. Aquatic Diptera, Part I. Nematocera exclusive of Chironomidae and Ceratopogonidae. Memoirs of the Cornell University Agricultural Experiment Station, 164:1-71.

Kalugina, N.S. 1985. Infraorders Psychodomorpha, Tipulomorpha and Culicomorpha. Dvukrylye nasekomye Yury Sibiri, p. 33-113. In Kalugina, N.S. and Kovalev, V.G. (eds.), The Diptera of the Jurassic of Siberia. Akademia Nauk USSR, Moscow.

Krzeminski, W. and Jarzembowski, E. 1999. Aenne triassica, n. sp., the oldest representative of Chironomidae. Polskie Pismo Entomologiczne, 68:445-449.

Lane, J. 1939. Notes on non hematophagous Culicidae. Boletim Biologico, Clube Zoologico do Brasil, 4:99113.

Lane, J. 1942. Dixinae e Chaoborinae. Revisao das especies neotropicas (Diptera, Culicidae). Revista de Entomologia, 13:81-148.

Linnæus, C. 1758. Systema naturæ per regna tria naturæ, secundum classes, ordines, genera, species, cum characteribus, differentiis, synonymis, locis. Tomus I. Editio decima, reformata. Holmiæ. (Salvius).

Loew, H. 1849. Cylindrotoma nigriventris, Dixa laeta, Dixa puberula und Dixa obscura, vier neue Arten. Stettiner Entomologische Zeitung, 10:341-349.

Loew, H. 1863. Diptera Americae septentrionalis indigena. Centuria tertia. Berliner entomologische Zeitschrift, 7:1-55.

Lukashevich, E.D. 1996. Mesozoic Dixidae (Insects: Diptera) and systematic position of Dixamima Rohdendorf, 1964 and Rhaetomyia Rohdendorf, 1962. Paleontological Journal, 30:46-51.

Lukashevich, E.D., Coram, R.A., and Jarzembowski, E.A. 2001. New true flies (Insecta: Diptera) from the Lower Cretaceous of southern England. Cretaceous Research, 22:451-460.

Martini, E. 1929. 11. Dixidae. - 12. Culicidae. p. 145320. In Lindner, E. (ed.), Die Fliegen der palaearktischen region. Stuttgart.

McAlpine, J.F. 1981. Morphology and terminology adult, p. 9-63. In McAlpine, J.F., Peterson, B.V., Shewell, G.E., Teskey, H.J., Vockeroth, J.R. and Wood, D.M. (eds.), Manual of Nearctic Diptera, Monograph No. 27. Research Branch Agriculture Canada, Ottawa.

Meigen, J.W. 1818. Systematische Beschreibung der bekannten europäischen zweiflügeligen Insekten. Erster Theil. F.W. Forstmann, Aachen.

Meigen, J.W. 1830. Systematische Beschreibung der bekannten europaischen zweiflugeligen Insekten. Sechster Theil. Schulz, Hamm. 
Meigen, J.W. 1838. Systematische Beschreibung der bekannten europaischen zweiflugeligen Insekten. Siebenter Theil oder Supplementband. Schultz, Hamm.

Melander, A.L. 1916. The dipterous family Scatopsidae. Bulletin of the Washington Agricultural Experiment Station, 130:1-21.

Meunier, F. 1906. Monographie des Tipulidae et Dixidae de l'ambre de la Baltique. Annales des Sciences Naturelles Zoologie et Paleontologie (Serial 9), 4:349-401.

Meunier, F. 1915. Nouvelles recherches sur quelques Insectes des platrieres d'Aix en Provence. Verhandelingen der Koninklijke Akademie van Wetenschappen te Amsterdam, 18:1-17.

Moulton, J.K. 2016. The Dixa inextricata Dyar \& Shannon (Diptera: Dixidae) species group, with two new cryptic species from the eastern Nearctic Region. Zootaxa, 4121(4):458-472.

Nowell, W.R. 1951. The dipterous family Dixidae in Western North America (Insecta: Diptera). Microentomology, 16:187-270.

Nowell, W.R. 1980. A new species of Dixa from peninsular Thailand (Diptera: Dixidae). Pacific Insects, 22:174-177.

Oosterbroek, P. and Courtney, G. 1995. Phylogeny of the nematocerous families of Diptera (Insecta). Zoological Journal of the Linnean Society, 115:267-311.

Pandazis, G. 1933. Dixinae and Chaborinae of Greece. Praktika tes Akademias Athenon, 8:67-70.

Pape, T., Blagoderov, V., and Mostovski, M.B. 2011. Order Diptera Linnaeus, 1758. Zootaxa, 3148:222229.

Pape, T. and Thompson, F.C. 2013. Dixidae. Systema Dipterorum, Version 1.5. 1 record. http://www.diptera.org/, accessed on 19 September 2016.

Papp, L. 2007. Dixidae, Axymyiidae, Mycetobiidae, Keroplatidae, Macroceridae and Ditomyiidae (Diptera) from Taiwan. Acta Zoologica Academiae Scientiarum Hungaricae, 53:273-294.

Papp, L., Merz, B., and Foldvari, M. 2006. Diptera of Thailand - A summary of the families and genera with references to the species representations. Acta Zoologica Academiae Scientiarum Hungaricae, 52:97-269.

Perkovsky, E.E., Zosimovich, V.Y., and Vlaskin, A.P. 2010. Rovno amber, p. 116-136. In Penney D. (ed.), Biodiversity of fossils in amber from the major world deposits. Siri Scientific Press, Manchester.

Peters, T.M. 1980. A new species of Dixella (Diptera: Dixidae) from Honduras, Central America. Proceedings of the Entomological Society of Washington, 82:681-684

Peters, T.M. 1981. Dixidae, p. 329-332. In McAlpine, J.F., Peterson, B.V., Shewell, G.E., Teskey, H.J., Vockeroth, J.R., and Wood, D.M. (eds.), Manual of Nearctic Diptera, Monograph No. 27. Research Branch Agriculture Canada, Ottawa.
Peters, T.M. 1992. Two new Dixidae (Diptera) from North Korea. Proceedings of the Entomological Society of Washington, 94:157-161.

Peters, T.M. 1993. Two new Dixidae (Diptera) from South Korea. Proceedings of the Entomological Society of Washington, 95:17-20.

Peters, T.M. and Cook E.F. 1966. The Nearctic Dixidae (Diptera). Miscellaneous Publications of the Entomological Society of America, 5:233-278.

Peters, T.M., and Savary, R.W. 1994. A new genus of Dixidae (Diptera) from the Philippines. Proceedings of the Entomological Society of Washington, 96:2226.

Peus, F. 1936. Zur Kenntnis der Dixiden-Fauna Nordeuropas (Diptera, Namatoc.). Norsk Entomologisk Tidsskrift, 4:117-127.

Poinar, G.O. Jr 1992. Life in Amber. Stanford University Press, Stanford

Rao, P.N. and Rai, K.S. 1987. Comparative karyotypes and chromosomal evolution in some genera of nematocerous (Diptera: Nematocera) families. Annals of the Entomological Society of America, 80:321-332.

Rao, P.N. and Rai, K.S. 1990. Genome evolution in the mosquitoes and other closely related members of the superfamily Culicoidea. Hereditas, 113:139-144.

Ross, H.H. 1951. Conflict with Culex. Mosquito News, $11: 128-132$.

Saether, O.A. 2000. Phylogeny of Culicomorpha. Systematic Entomology, 25:223-234.

Schiner, I.R. 1868. Diptera, p. 1-388. In von WullerstorfUrbair, B. (ed.), Reise der österreichischen Fregatte Novara. Zoologie, 2(1). B.K. Gerold's Sohn, Wien.

Seguy, E. 1921. Sur deux nouveaux Dixa et synopsis des males des especes de France (Dipt. culicidae). Bulletin de la Société entomologique de France, 1921:199-206.

Shockley, F.W. and Greenwalt, D. 2013. Ptenidium kishenehnsis, a new fossil described from the Kishenehn oil shales (Coleoptera: Ptiliidae), with a checklist of previously known fossil ptiliids. Proceedings of the Entomological Society of Washington, 115:173-181.

Smith, F.K. 1938. Larval characters of genus Dixa. Journal of the New York Entomological Society, 36:263286.

Taber, S.W. 2010. A new species of Dixella Dyar \& Shannon meniscus midge (Diptera: Dixidae). Southwestern Entomologist, 35:295-307.

Takahashi, M. 1958. Revision of Japanese Dixidae. Mushi, 32:1-18.

Theobald, N. 1937. Les insectes fossiles des terrains Oligocenes de France. Bulletin Mensuel de la Société des Sciences de Nancy, 2:1-473.

Tonnoir, A.L. 1924. New Zealand Dixidae. Records of the Canterbury Museum, 2:221-233.

Tonnoir, A.L. 1925. New Zealand Dixidae (Dipt.). (Addition and correction). Records of the Canterbury Museum, 2:311.

Wagner, R., Friedberg, A., and Ortal R. 1991/1992. The Dixidae (Diptera: Nematocera) of Israel and Egypt 
with a new record from Greece. Israel Journal of Entomology, 25-26:163-176.

Walker, F. 1848. List of the specimens of dipterous insects in the collection of the British Museum. part 1. British Museum, London.

Wiegmann, B.M., Trautwein, M.D., Winkler, I.S., Barr, N.B., Kim, J., Lambkin, C., Bertone, M.A., Cassel, B.K., Bayless, K.M., Heimberg, A.M., Wheeler, B.M., Peterson, K.J., Pape, T., Sinclair, B.J., Skevington, J.H., Blagoderov, V., Caravas, J., Kutty, S.N., Schmidt-ott, U., Kampmeier, G.E., Thompson, F.C., Grimaldi, D.A., Beckenbach, A.T., Courtney, G.W., Friedrich, M., Meier, R., and Yeates, D.K. 2011. Episodic radiations in the fly tree of life. Proceedings of the United States National Academy of Sciences, 108:5690-5695.

Wood, D.M. and Borkent, A. 1989. Phylogeny and classification of the Nematocera, p. 1333-1370. In McAlpine, J.F. (ed.), Manual of Nearctic Diptera, Vol. 3, Monograph No. 32. Research Branch Agriculture Canada, Ottawa.

Woodley, N.E., Borkent, A., and Wheeler, T.A. 2009. Phylogeny of the Diptera, p. 79-94. In Brown, B.V., Borkent, A., Cumming, J.M., Wood, D.M., Woodley, N.E., and Zumbado, M.A. (eds.), Manual of Central American Diptera. NRC Research Press, Ottawa, CA. 
APPENDIX 1.

Taxa examined in wing venation variability analysis. $\dagger$ denotes an extinct taxon.

\begin{tabular}{|c|c|}
\hline Taxon & Reference/Depository \\
\hline Asiodixa pura & Papp et al., 2006 \\
\hline Asiodixa maculosa & Papp et al., 2006 \\
\hline Dixa aliciae & WRBU \\
\hline Dixa babai & Takahashi, 1958 \\
\hline Dixa brevis & WRBU \\
\hline Dixa californica & WRBU \\
\hline Dixa camerounensis & WRBU \\
\hline Dixa cimbricat & Ansorge, 1992 \\
\hline Dixa clavata & WRBU \\
\hline Dixa dilatata & WRBU \\
\hline Dixa dyari & WRBU \\
\hline Dixa fluvica & WRBU \\
\hline Dixa fusca & WRBU \\
\hline Dixa hegemonica & WRBU \\
\hline Dixa hikosana & Takahashi, 1958 \\
\hline Dixa hoffmani & WRBU \\
\hline Dixa inextricata & WRBU \\
\hline Dixa johannseni & WRBU \\
\hline Dixa kaplani & Wagner et al., 1991/1992 \\
\hline Dixa kyushuensis & Takahashi, 1958 \\
\hline Dixa lobata & WRBU \\
\hline Dixa lobatus & WRBU \\
\hline Dixa longistyla & Takahashi, 1958 \\
\hline Dixa lunata & WRBU \\
\hline Dixa maculata & WRBU \\
\hline Dixa melanderi & WRBU \\
\hline Dixa minuta & Hennig, 1966 \\
\hline Dixa minutiformis & Takahashi, 1958 \\
\hline Dixa modesta & Johannsen, 1923 \\
\hline Dixa modesto & WRBU \\
\hline Dixa naevia & WRBU \\
\hline Dixa nebulosa & WRBU \\
\hline Dixa neoaliciae & WRBU \\
\hline Dixa neohegemonica & WRBU \\
\hline Dixa nipponica & Takahashi, 1958 \\
\hline Dixa notata & WRBU \\
\hline Dixa nova & Peters, 1981 \\
\hline Dixa nubilipennis & WRBU \\
\hline Dixa obtusa & Takahashi, 1958 \\
\hline Dixa orientale & WRBU \\
\hline Dixa prisculat & Cockerell, 1921 \\
\hline Dixa puberula & Disney, 1975 \\
\hline Dixa punctata & Wagner et al., 1991/1992 \\
\hline
\end{tabular}




\begin{tabular}{|c|c|}
\hline Taxon & Reference/Depository \\
\hline Dixa rathyme & WRBU \\
\hline Dixa serrata & WRBU \\
\hline Dixa serrifera & WRBU \\
\hline Dixa similis & WRBU \\
\hline Dixa spiralis & WRBU \\
\hline Dixa stuckenbergi & WRBU \\
\hline Dixa submaculata & WRBU \\
\hline Dixa subobscura & Takahashi, 1958 \\
\hline Dixa terna & WRBU \\
\hline Dixa tertiariat & Theobald, 1937 \\
\hline Dixa trilineata & Takahashi, 1958 \\
\hline Dixa xavia & WRBU \\
\hline Dixa yamatona & Takahashi, 1958 \\
\hline Dixella aegyptiaca & Wagner et al., 1991/1992 \\
\hline Dixella aestivalis & WRBU \\
\hline Dixella amphibia & Disney, 1975 \\
\hline Dixella attica & Wagner et al., 1991/1992 \\
\hline Dixella aurora & WRBU \\
\hline Dixella autumnalis & WRBU \\
\hline Dixella corensis & Peters, 1992 \\
\hline Dixella cornuta & WRBU \\
\hline Dixella curvistylat & This study \\
\hline Dixella deltoura & WRBU \\
\hline Dixella distanst & Hennig, 1966 \\
\hline Dixella eomarginata & This study \\
\hline Dixella fernandezae & Chaverri and Borkent, 2007 \\
\hline Dixella filicornis & Disney, 1975 \\
\hline Dixella filiforcepst & Hennig, 1966 \\
\hline Dixella fraxina & Taber, 2010 \\
\hline Dixella fuscifrons & Wagner et al., 1991/1992 \\
\hline Dixella fuscinervis & WRBU \\
\hline Dixella golanensis & Wagner et al., 1991/1992 \\
\hline Dixella hansoni & Chaverri and Borkent, 2007 \\
\hline Dixella hernandezi & Chaverri and Borkent, 2007 \\
\hline Dixella indiana & Peters and Cook, 1966 \\
\hline Dixella intacta† & This study \\
\hline Dixella israelis & Wagner et al., 1991/1992 \\
\hline Dixella jironi & Chaverri and Borkent, 2007 \\
\hline Dixella laeta & Peus, 1936 \\
\hline Dixella limai & WRBU \\
\hline Dixella lobata & Chaverri and Borkent, 2007 \\
\hline Dixella maculata & Chaverri and Borkent, 2007 \\
\hline Dixella martini & WRBU \\
\hline Dixella neozelandica & Belkin, 1968 \\
\hline Dixella nixiae & Peters, 1980 \\
\hline Dixella obscura & WRBU \\
\hline
\end{tabular}




\begin{tabular}{ll}
\hline \multicolumn{1}{c}{ Taxon } & \multicolumn{1}{c}{ Reference/Depository } \\
\hline Dixella pollex & Nowell, 1980 \\
Dixella pyrenaica & Peus, 1936 \\
Dixella scitula & Belkin et al., 1970 \\
Dixella serotina & Disney, 1975 \\
Dixella shannoni & Chaverri and Borkent, 2007 \\
Dixella solomonis & WRBU \\
Dixella spinilobatat & This study \\
Dixella succineat & Hennig, 1966 \\
Dixella suzukii & Chaverri and Borkent, 2007 \\
Dixella techana & WRBU \\
Dixella torrential & WRBU \\
Dixella trinitensis & WRBU \\
Dixella venezulensis & Chaverri and Borkent, 2007 \\
Dixella vespertina & WRBU \\
Dixella woodi & Chaverri and Borkent, 2007 \\
Eucorethrina convexat & Lukashevich, 1996 \\
Eucorethrina flexat & Kalugina, 1985, Lukashevich, 1996 \\
Eucorethrina westwoodit & Lukashevich et al., 2001 \\
Meringodixa chalonensis & Nowell, 1951 \\
Mesodixa biambulacra & Belkin et al., 1970 \\
Neodixa minuta & Belkin, 1962 \\
Nothodixa campbelli & Belkin, 1968 \\
Nothodixa otagensis & Belkin, 1962 \\
Nothodixa septentrionalis & Belkin, 1962 \\
Nothodixa philpotti & Lelkin, 1962 \\
Syndixa mollist & \\
Syndixa sibiricat & Lukashevich, 1996 \\
\hline
\end{tabular}




\section{APPENDIX 2.}

Character states used in the analysis of fossil and extant dixid wing venation.

1. Vein Sc apex relative to the origin of Rs: basal [ $>2 X$ vein width] $(0)$; subbasal $[<2 X$ vein width] (1); even (2); subapical $[<2 X$ vein width] (3); apical [>2X vein width] (4).

2. Crossvein $r-m$ origin relative to the bifurcation of Rs: basal $(0)$; subbasal $[<2 X$ vein width] (1); even (2); subapical $[<2 X$ vein width] (3); apical (4).

3. Crossvein $\mathrm{m}$-cu origin relative to the terminus of $r-m$ : basal $(0)$; subbasal $[<2 X$ vein width] (1); even (2); subapical $[<2 X$ vein width] (3); apical (4).

4. Vein $A_{1}$ terminus relative to the origin of Rs: basal (0); subbasal [ $<2 X$ vein width] (1); even (2); subapical $[<2 X$ vein width] (3); apical (4).

5. Vein $A_{1}$ terminus relative to Sc terminus: basal (0); subasal [ $<2 X$ vein width] (1); even with (2); subapical [ $<2 X$ vein width] (3); apical (4).
6. Vein $A_{1}$ terminus relative to the bifurcation of Cu: basal (0); subbasal [<2X vein width] (1); even (2); subapical [ $<2 X$ vein width] (3); apical (4).

7. Vein $\mathrm{R}_{2+3}$ : branched (0); unbranched (1).

8. $\mathrm{R}_{2+3}$ curvature: straight or very slightly arched (0); strongly arched (1).

9. Vein $\mathrm{R}_{2+3}$ branch relative to the bifurcation of M: basal (0); subbasal $[<2 X$ vein width] basal (1); even (2); subapical [<2X vein width] (3); apical (4).

10. Vein $R_{1}$ : fused to $C$ far basal (near $3 / 4$ wing length) of wing apex (0); closer to $C$ than $R_{2}$ and fused near wing apex (1); equidistant to $C$ and $R_{2}$ and fused near wing apex (2).

11. Vein $\mathrm{R}_{2}$ : not fused with $\mathrm{R}_{1}(0)$; fused with $\mathrm{R}_{1}$ (1).

12. Rs: straight (0); sigmoidal (1).

13. Wing length/width: $<2.5(0) ; 2.5-3(1) ;>3<4$ (2) $>4$ (3). 
APPENDIX 3.

Morphological data matrix (Dixidae wing and venation characters only).

\begin{tabular}{|c|c|c|c|c|c|c|c|c|c|c|c|c|c|}
\hline Taxon & 1 & 2 & 3 & 4 & 5 & 6 & 7 & 8 & 9 & 10 & 11 & 12 & 13 \\
\hline Dixa aliciae & 2 & 1 & 2 & 2 & 2 & 0 & 0 & 1 & 4 & 1 & 0 & 0 & - \\
\hline Dixa babai & 0 & - & 4 & 4 & 4 & 0 & 0 & 1 & 0 & 1 & 0 & 0 & 1 \\
\hline Dixa brevis & 2 & 4 & 4 & 4 & 4 & 0 & 0 & 1 & 0 & 1 & 0 & 0 & 0 \\
\hline Dixa californica & 3 & 2 & 4 & 4 & 4 & 0 & 0 & 1 & 2 & 1 & 0 & 0 & - \\
\hline Dixa camerounensis & 0 & 4 & 4 & 2 & 4 & 0 & 0 & 1 & 0 & 1 & 0 & 0 & - \\
\hline Dixa clavata & 2 & 3 & 4 & 4 & 4 & 0 & 0 & 1 & 0 & 1 & 0 & 0 & - \\
\hline Dixa dilatata & 0 & 3 & 4 & 4 & 4 & 0 & 0 & 1 & 3 & 1 & 0 & 0 & - \\
\hline Dixa dyari & 0 & 2 & 4 & 4 & 4 & 0 & 0 & 1 & 4 & 1 & 0 & 0 & - \\
\hline Dixa fluvica & 1 & 2 & 4 & 4 & 4 & 0 & 0 & 1 & 0 & 1 & 0 & 0 & - \\
\hline Dixa fusca & 0 & 3 & 4 & 4 & 4 & 0 & 0 & 1 & 0 & 1 & 0 & 0 & - \\
\hline Dixa hegemonica & 1 & 3 & 4 & 4 & 4 & 0 & 0 & 1 & 2 & 1 & 0 & 0 & - \\
\hline Dixa hikosana & 0 & - & 4 & 4 & 4 & 0 & 0 & 1 & 0 & 1 & 0 & 0 & 1 \\
\hline Dixa hoffmani & 0 & 2 & 0 & 4 & 4 & 0 & 0 & 1 & 4 & 1 & 0 & 0 & - \\
\hline Dixa inextricata & 2 & 2 & 4 & 4 & 4 & 0 & 0 & 1 & 0 & 1 & 0 & 0 & - \\
\hline Dixa johannseni & 4 & 2 & 4 & 4 & 4 & 0 & 0 & 1 & 0 & 1 & 0 & 0 & - \\
\hline Dixa kaplani & 0 & 2 & 0 & 2 & 4 & 0 & 0 & 1 & 3 & 1 & 0 & 0 & 1 \\
\hline Dixa kyushuensis & 0 & 2 & 4 & 4 & 4 & 0 & 0 & 1 & 4 & 1 & 0 & 0 & 1 \\
\hline Dixa lobata & 4 & 2 & 4 & 4 & 4 & 2 & 0 & 1 & 0 & 1 & 0 & 0 & - \\
\hline Dixa lobatus & 2 & 4 & 4 & 4 & 4 & 0 & 0 & 1 & 0 & 1 & 0 & 0 & - \\
\hline Dixa longistyla & 0 & 0 & 4 & 0 & 4 & 0 & 0 & 1 & 4 & 1 & 0 & 0 & 1 \\
\hline Dixa lunata & 0 & 4 & 4 & 4 & 4 & 0 & 0 & 1 & 4 & 1 & 0 & 0 & - \\
\hline Dixa maculata & 0 & 4 & 4 & 4 & 4 & 0 & 0 & 1 & 4 & 1 & 0 & 0 & - \\
\hline Dixa melanderi & 2 & 4 & 4 & 4 & 4 & 0 & 0 & 1 & 4 & 1 & 0 & 0 & - \\
\hline Dixa minutiformis & 0 & 3 & 4 & 4 & 4 & 2 & 0 & 1 & 0 & 1 & 0 & 0 & 1 \\
\hline Dixa modesta & 0 & 4 & 4 & 2 & 4 & 0 & 0 & 1 & 0 & 1 & 0 & 0 & 2 \\
\hline Dixa modesto & 0 & 4 & 4 & 4 & 3 & 0 & 0 & 1 & 4 & 1 & 0 & 0 & - \\
\hline Dixa naevia & 2 & 2 & 4 & 4 & 4 & 0 & 0 & 1 & 4 & 1 & 0 & 0 & - \\
\hline Dixa nebulosi & 0 & 2 & 4 & 4 & 4 & 0 & 0 & 1 & 2 & 1 & 0 & 0 & - \\
\hline Dixa neoaliciae & 0 & 0 & 0 & 4 & 4 & 1 & 0 & 1 & 4 & 1 & 0 & 0 & - \\
\hline Dixa neohegemonica & 0 & 4 & 4 & 4 & 4 & 0 & 0 & 1 & 2 & 1 & 0 & 0 & - \\
\hline Dixa nipponica & 0 & - & 4 & 4 & 0 & 0 & 0 & 1 & 4 & 1 & 0 & 0 & 1 \\
\hline Dixa notata & 0 & 4 & 4 & 4 & 4 & 0 & 0 & 1 & 0 & 1 & 0 & 0 & - \\
\hline Dixa nubilipennis & 0 & 4 & 4 & 2 & 4 & 0 & 0 & 1 & 0 & 1 & 0 & 0 & - \\
\hline Dixa obtusa & 0 & - & 4 & 4 & 4 & 0 & 0 & 1 & 0 & 1 & 0 & 0 & 1 \\
\hline Dixa orientale & 4 & 3 & 4 & 4 & 4 & 0 & 0 & 1 & 4 & 1 & 0 & 0 & - \\
\hline Dixa puberula & 1 & 3 & 4 & 4 & 4 & 1 & 0 & 1 & 2 & 1 & 0 & 0 & 1 \\
\hline Dixa punctata & 0 & 2 & 0 & 2 & 4 & 0 & 0 & 1 & 2 & 1 & 0 & 0 & 2 \\
\hline Dixa rhathyme & 2 & 3 & 4 & 4 & 4 & 1 & 0 & 1 & 1 & 1 & 0 & 0 & - \\
\hline Dixa serrata & 0 & 2 & 4 & 4 & 4 & 0 & 0 & 1 & 0 & 1 & 0 & 0 & - \\
\hline Dixa serrifera & 0 & 4 & 4 & 3 & 4 & 0 & 0 & 1 & 3 & 1 & 0 & 0 & - \\
\hline Dixa similis & 0 & 4 & 4 & 4 & 4 & 0 & 0 & 1 & 2 & 1 & 0 & 0 & - \\
\hline Dixa spiralis & 0 & 0 & 4 & 2 & 4 & 0 & 0 & 1 & 0 & 1 & 0 & 0 & - \\
\hline
\end{tabular}




\begin{tabular}{|c|c|c|c|c|c|c|c|c|c|c|c|c|c|}
\hline Taxon & 1 & 2 & 3 & 4 & 5 & 6 & 7 & 8 & 9 & 10 & 11 & 12 & 13 \\
\hline Dixa stuckenbergi & 0 & 0 & 4 & 1 & 4 & 0 & 0 & 1 & 4 & 1 & 0 & 0 & - \\
\hline Dixa submaculata & 1 & 3 & 4 & 4 & 4 & 0 & 0 & 1 & 4 & 1 & 0 & 0 & - \\
\hline Dixa subobscura & 0 & 0 & 4 & 4 & 4 & 0 & 0 & 1 & 0 & 1 & 0 & 0 & 1 \\
\hline Dixa terna & 0 & 3 & 4 & 4 & 4 & 0 & 0 & 1 & 0 & 1 & 0 & 0 & - \\
\hline Dixa trilineata & 0 & - & 4 & 4 & 4 & 2 & 0 & 1 & 4 & 1 & 0 & 0 & 1 \\
\hline Dixa xavia & 0 & 4 & 4 & 4 & 4 & 0 & 0 & 1 & 4 & 1 & 0 & 0 & - \\
\hline Dixa yamatona & 0 & - & 4 & 4 & 4 & 1 & 0 & 1 & 2 & 1 & 0 & 0 & 1 \\
\hline Dixa priscula & 0 & 2 & 0 & 4 & 4 & 0 & 0 & 1 & 0 & 1 & 0 & 0 & 2 \\
\hline Dixa cimbrica & 1 & 4 & 0 & 4 & 4 & 2 & 0 & 1 & 4 & 1 & 0 & 0 & 0 \\
\hline Dixa minuta & 0 & 0 & 2 & - & - & - & 0 & 1 & 4 & 1 & 0 & 0 & 1 \\
\hline Dixa tertiaria & 0 & 0 & 1 & 3 & 4 & 1 & 0 & 1 & 4 & 1 & 0 & 0 & 2 \\
\hline Dixella aegyptiaca & 0 & 1 & 4 & 4 & 4 & 0 & 0 & 1 & 2 & 1 & 0 & 0 & 2 \\
\hline Dixella aestivalis & 0 & 0 & 4 & 4 & 4 & 0 & 0 & 1 & 0 & 1 & 0 & 0 & - \\
\hline Dixella amphibia & 2 & 4 & 4 & 4 & 4 & 0 & 0 & 1 & 1 & 1 & 0 & 0 & 1 \\
\hline Dixella attica & 3 & 2 & 4 & 4 & 4 & 0 & 0 & 1 & 4 & 1 & 0 & 0 & 0 \\
\hline Dixella aurora & 0 & 4 & 3 & 4 & 4 & 0 & 0 & 1 & 0 & 1 & 0 & 0 & - \\
\hline Dixella autumnalis & 0 & 2 & 4 & 4 & 4 & 0 & 0 & 1 & 0 & 1 & 0 & 0 & - \\
\hline Dixella corensis & 0 & 2 & 4 & 4 & 4 & 0 & 0 & 1 & 1 & 1 & 0 & 0 & - \\
\hline Dixella cornuta & 1 & 2 & 4 & 4 & 4 & 0 & 0 & 1 & 0 & 1 & 0 & 0 & - \\
\hline Dixella deltoura & 0 & 2 & - & 4 & 4 & 0 & 0 & 1 & 0 & 1 & 0 & 0 & - \\
\hline Dixella fernandezae & 0 & 0 & 3 & 4 & 4 & 0 & 0 & 1 & 0 & 1 & 0 & 0 & 1 \\
\hline Dixella filicornis & 0 & 0 & 4 & 4 & 4 & 2 & 0 & 1 & 1 & 1 & 0 & 0 & 0 \\
\hline Dixella fraxina & 0 & 3 & 4 & 4 & 4 & 0 & 0 & 1 & 0 & 1 & 0 & 0 & 1 \\
\hline Dixella fuscifrons & 0 & 4 & 4 & 4 & 4 & 0 & 0 & 1 & 0 & 1 & 0 & 0 & 1 \\
\hline Dixella fuscinervis & 4 & 4 & 4 & 4 & 4 & 0 & 0 & 1 & 0 & 1 & 0 & 0 & - \\
\hline Dixella golanensis & 2 & 4 & 4 & 4 & 4 & 2 & 0 & 1 & 4 & 1 & 0 & 0 & 1 \\
\hline Dixella hansoni & 0 & 0 & 2 & 4 & 4 & 0 & 0 & 1 & 1 & 1 & 0 & 0 & 1 \\
\hline Dixella hernandezi & 4 & 4 & 2 & 4 & 3 & 0 & 0 & 1 & 1 & 1 & 0 & 0 & 1 \\
\hline Dixella indiana & 0 & 4 & 4 & 4 & 4 & 0 & 0 & 1 & 0 & 1 & 0 & 0 & 2 \\
\hline Dixella israelis & 0 & 4 & 4 & 4 & 4 & 4 & 0 & 1 & 0 & 1 & 0 & 0 & 2 \\
\hline Dixella jironi & 0 & 2 & 2 & 4 & 4 & 0 & 0 & 1 & 0 & 1 & 0 & 0 & 1 \\
\hline Dixella laeta & 4 & 0 & 4 & 4 & 4 & 0 & 0 & 1 & 2 & 1 & 0 & 0 & - \\
\hline Dixella limai & 0 & 2 & 0 & 4 & 4 & 0 & 0 & 1 & 0 & 1 & 0 & 0 & - \\
\hline Dixella lobata & 0 & 2 & 2 & 4 & 4 & 0 & 0 & 1 & - & 1 & 0 & 0 & 1 \\
\hline Dixella maculata & 4 & 2 & 4 & 2 & 0 & 0 & 0 & 1 & 2 & 1 & 0 & 0 & 1 \\
\hline Dixella martini & 0 & 4 & 4 & 4 & 4 & 0 & 0 & 1 & 4 & 1 & 0 & 0 & - \\
\hline Dixella neozelandica & 1 & 4 & 4 & 4 & 4 & 0 & 0 & 1 & 0 & 1 & 0 & 0 & 2 \\
\hline Dixella nixiae & 0 & 2 & 1 & 4 & 4 & 0 & 0 & 1 & 4 & 1 & 0 & 0 & 1 \\
\hline Dixa nova & 4 & 3 & 4 & 4 & 4 & 0 & 0 & 1 & 4 & 1 & 0 & 0 & 2 \\
\hline Dixella obscura & 0 & 4 & 4 & 4 & 4 & 0 & 0 & 1 & 0 & 1 & 0 & 0 & - \\
\hline Dixella pollex & 0 & 4 & 4 & 0 & 4 & 0 & 0 & 1 & 2 & 1 & 0 & 0 & 1 \\
\hline Dixella pyrenaica & 0 & 0 & 4 & 4 & 4 & 2 & 0 & 1 & 4 & 1 & 0 & 0 & - \\
\hline Dixella scitula & 2 & 4 & 0 & 4 & 4 & 0 & 0 & 1 & 0 & 1 & 0 & 0 & 2 \\
\hline Dixella serotina & 0 & 3 & 4 & 4 & 4 & 1 & 0 & 1 & 0 & 1 & 0 & 0 & 1 \\
\hline Dixella shannoni & 4 & 0 & 2 & 4 & 0 & 0 & 0 & 1 & 0 & 1 & 0 & 0 & 1 \\
\hline Dixella solomonis & 2 & 0 & 4 & 4 & 4 & 0 & 0 & 1 & 2 & 1 & 0 & 0 & - \\
\hline
\end{tabular}




\begin{tabular}{llllllllllllll}
\hline \multicolumn{1}{c}{ Taxon } & $\mathbf{1}$ & $\mathbf{2}$ & $\mathbf{3}$ & $\mathbf{4}$ & $\mathbf{5}$ & $\mathbf{6}$ & $\mathbf{7}$ & $\mathbf{8}$ & $\mathbf{9}$ & $\mathbf{1 0}$ & $\mathbf{1 1}$ & $\mathbf{1 2}$ & $\mathbf{1 3}$ \\
\hline Dixella suzukii & 0 & 2 & 0 & 4 & 4 & 0 & 0 & 1 & 2 & 1 & 0 & 0 & 1 \\
Dixella techana & 0 & 4 & 0 & 4 & 4 & 0 & 0 & 1 & 3 & 1 & 0 & 0 & - \\
Dixella torrentia & 0 & 2 & 0 & 4 & 4 & 4 & 0 & 1 & 0 & 1 & 0 & 0 & - \\
Dixella trinitensis & 0 & 0 & 4 & 0 & 4 & 0 & 0 & 1 & 4 & 1 & 0 & 0 & - \\
Dixella venezulensis & 0 & 0 & 4 & 4 & 4 & 0 & 0 & 1 & 0 & 1 & 0 & 0 & 1 \\
Dixella vespertina & 1 & 3 & 2 & 4 & 4 & 0 & 0 & 1 & 0 & 1 & 0 & 0 & - \\
Dixella woodi & 2 & 0 & 4 & 4 & 4 & 0 & 0 & 1 & 0 & 1 & 0 & 0 & 1 \\
Dixella spinilobata & 0 & - & - & - & - & - & 0 & 1 & - & 1 & 0 & 0 & 2 \\
Dixella eomarginata & 2 & 3 & 2 & 4 & 4 & 0 & 0 & 1 & 1 & 1 & 0 & 0 & 1 \\
Dixella curvistyla & 0 & 0 & 3 & - & - & - & 0 & 1 & 0 & 1 & 0 & 0 & 0 \\
Dixella intacta & 2 & 3 & 2 & 0 & 0 & 0 & 0 & 1 & 0 & 1 & 0 & 0 & 2 \\
Dixella distans & 0 & 3 & 4 & 4 & 4 & 4 & 0 & 1 & 4 & 1 & 0 & 0 & - \\
Dixella filiforceps & 0 & 2 & 3 & 4 & 4 & 2 & 0 & 1 & 4 & 1 & 0 & 0 & - \\
Dixella succinea & 0 & 2 & 4 & 4 & 4 & 1 & 0 & 1 & 4 & 1 & 0 & 0 & 1 \\
Mesodixa biambulacra & 1 & 2 & 3 & 4 & 4 & 0 & 0 & 1 & 2 & 1 & 0 & 0 & 1 \\
Meringodixa chalonensis & 2 & 4 & 4 & 4 & 4 & 1 & 0 & 1 & 2 & 1 & 0 & 0 & 1 \\
Neodixa minuta & 0 & 0 & 4 & 4 & 4 & 0 & 1 & 1 & 0 & 1 & 0 & 0 & 1 \\
Asiodixa pura & 0 & 0 & 3 & 2 & 4 & 0 & 0 & 1 & 0 & 1 & 0 & 1 & 0 \\
Asiodixa maculosa & 0 & 0 & 4 & 0 & 4 & 0 & 0 & 1 & 0 & 1 & 0 & 1 & 1 \\
Nothodixa campbelli & 0 & 0 & 4 & 4 & 4 & 0 & 0 & 1 & 4 & 1 & 0 & 0 & 0 \\
Nothodixa otagensis & 0 & 0 & 4 & 4 & 4 & 2 & 0 & 1 & 4 & 1 & 0 & 0 & 1 \\
Nothodixa septentrionalis & 0 & 0 & 4 & 4 & 4 & 0 & 0 & 1 & 1 & 1 & 0 & 0 & 0 \\
Nothodixa philpotti & 0 & 0 & 4 & 0 & 4 & 0 & 0 & 1 & 4 & 1 & 0 & 0 & 0 \\
Eucorethrina convexa & 4 & 4 & 2 & 4 & 3 & 0 & 0 & 0 & 0 & 2 & 0 & 0 & 0 \\
Eucorethrina flexa & 3 & 4 & 2 & 1 & 0 & 0 & 0 & 0 & 0 & 2 & 0 & 0 & 1 \\
Eucorethrina westwoodi & 4 & 4 & 2 & 4 & 2 & 0 & 0 & 0 & 0 & 2 & 0 & 0 & 0 \\
Syndixa mollis & 4 & 4 & 2 & 4 & 3 & 4 & 0 & 0 & 0 & - & 1 & 0 & 0 \\
Syndixa sibirica & 4 & 4 & 2 & 4 & 1 & 4 & 0 & 0 & 0 & - & 1 & 0 & 1 \\
\hline & & & & & & & & & & &
\end{tabular}

